\title{
Under arrest: cytostatic factor (CSF)-mediated metaphase arrest in vertebrate eggs
}

\author{
Brian J. Tunquist and James L. Maller ${ }^{1}$ \\ The Howard Hughes Medical Institute and Department of Pharmacology, University of Colorado School of Medicine, \\ Denver, Colorado 80262, USA
}

In most animals, the development of the immature oocyte into a fertilizable gamete, a process known as oocyte maturation, involves an arrest in the meiotic cell cycle while awaiting fertilization. Depending on the organism, this arrest can occur at the beginning of meiosis I, in metaphase of meiosis I, in metaphase of meiosis II, or, after the completion of meiosis altogether, in the pronuclear stage. In the case of the vertebrate oocyte, maturation begins at the $G_{2} / M$-phase border of meiosis $I$, and the arrest at the end of oocyte maturation occurs at metaphase of meiosis II. In vertebrates, premature arrest during oocyte maturation, as well as parthenogenetic release from the meiosis II arrest, is often the cause of infertility (Winston et al. 1991; Levran et al. 2002). In addition to gaining insight into the process of infertility, elucidation of the mechanism of meiotic arrest may increase our understanding of embryonic development, the molecular signal transduction pathways that operate in cell division, and cell cycle controls that may be altered in cancer cells.

Over 30 years ago, Yoshio Masui and Clement Markert (1971) published an historic paper describing cytoplasmic control over the behavior of nuclei of both meiotic and mitotic cells. This paper described an activity in the cytoplasm of eggs from the leopard frog Rana pipiens that was able to initiate oocyte maturation when injected into immature $\mathrm{G}_{2}$-arrested oocytes, an activity they termed maturation-promoting factor (MPF). In the same paper, Masui and Markert discovered that microinjection of the same egg cytoplasm into one blastomere of a two-cell embryo produced a cleavage arrest in the injected blastomere, whereas the uninjected blastomere continued to divide normally. They observed that the "mitotic apparatus" of the injected blastomere was "arrested at metaphase." As a control, cytoplasm taken from immature oocytes or early embryos did not inhibit cleavage of the injected blastomere. This led to the supposition that a "specific cytoplasmic factor or factors is

${ }^{1}$ Corresponding author.

E-MAIL Jim.Maller@uchsc.edu; FAX (303) 315-7160.

Article and publication are at http://www.genesdev.org/cgi/doi/10.1101/ gad.1071303. responsible for the inhibition of mitosis and cleavage. This hypothetical factor from the cytoplasm of maturing oocytes can be tentatively labeled 'cytostatic factor.'" Accordingly, the arrest of vertebrate eggs in meiosis II has since been renamed cytostatic factor (CSF) arrest, and the terms mature oocyte, metaphase-arrested oocyte, meiosis II-arrested oocyte, and CSF-arrested oocyte are synonymous with the term unfertilized egg.

CSF, by definition, does not describe a single molecule or protein, but rather an activity found in the egg. This cell division inhibitor must accumulate during oocyte maturation, must be capable of functioning in meiosis II, and must be inactivated on fertilization or parthenogenetic activation. Since 1971, numerous attempts have been made to identify $\operatorname{CSF}(\mathrm{s})$ in vertebrate eggs and to elucidate the molecular mechanism of the meiotic metaphase arrest. Much of the progress in our understanding of the biochemistry and cell biology of CSF arrest since then has come from studies using the denuded oocytes, embryos, and cell-free extracts of the South African clawed frog Xenopus laevis. Although not as extensively studied, the oocytes of higher vertebrates, such as mice, recapitulate most features of Xenopus oocyte maturation, and contain components of CSF activity homologous to those that have been identified in the Xenopus system (Masui 2000; Kubiak and Ciemerych 2001). To understand the genesis of CSF activity and the mechanism of its action, it is important to consider the biology and biochemistry of oocyte maturation.

\section{Xenopus oocyte maturation}

Fully grown, immature stage VI oocytes present in the ovaries of adult frogs are arrested at the $G_{2} / M$ transition of meiosis I. On progesterone (PG) secretion in vivo by the neighboring follicle cells of the ovary in response to pituitary hormones, or on PG addition in culture, the oocytes enter meiosis I and proceed with the process termed "oocyte maturation," ultimately resulting in a fertilizable egg (Fig. 1).

The biochemistry of oocyte maturation has been rigorously studied (for review, see Schmitt and Nebreda 2002). One reason for this comes from the discovery of 
Figure 1. Pathways involved in oocyte maturation. (A) Fully grown immature Xenopus oocytes are arrested at the $G_{2} / M$ border of the meiotic cell cycle. The steroid hormone progesterone overcomes this arrest and causes initiation of oocyte maturation. The oocytes enter meiosis I (MI), as witnessed by the appearance of a white spot in the center of the animal hemisphere due to the breakdown of the germinal vesicle (nuclear envelope), $\sim 3-4 \mathrm{~h}$ after progesterone stimulation. This is followed by a transient $50 \%$ decline in MPF activity and entry into meiosis II (MII), culminating with arrest in metaphase through an activity known as cytostatic factor (CSF). Fertilization of the egg overcomes CSF arrest, followed by exit from meiosis II and entry into the embryonic cell cycles. Two important signal transduction pathways crucial for the process of oocyte maturation are MPF (blue) and p42 MAPK (green; adapted from Ferrell 1999). (B) Pathway of MPF activation. Maturation-promoting factor (MPF) is a heterodimeric complex composed of a Cdc2 protein kinase subunit and a cyclin B regulatory subunit. MPF is found in an inactive form in immature oocytes due to phosphorylation on Thr 14 and Tyr 15 on Cdc2 by the dual-specificity inhibitory kinase Myt1. Progesterone stimulation of the immature oocyte brings about the activation of a dual specificity protein phosphatase, Cdc25C, that directly counteracts the Myt1 phosphorylation of MPF, leading to its activation. Progesterone also activates pathways that inhibit the Myt1 kinase. MPF activity is crucial for the process of oocyte maturation by acting pleiotropically to induce chromosome condensation, germinal vesicle breakdown (GVBD), and formation of the meiotic spindle, thus driving entry into $M$ phase. $(C)$ Activation of the MAPK pathway during oocyte maturation. Progesterone stimulation of the immature oocyte leads to the synthesis of the MAPK kinase kinase (MAPKKK), Mos, from maternal mRNA. Mos activates the MAPK kinase MEK1, which activates MAPK, and MAPK activates the serine/threonine protein kinase p90 Rsk. The MAPK pathway facilitates the MPF-driven process of oocyte maturation by contributing to the inhibition of Myt1 during meiosis I. As discussed in the text, this pathway is also crucial for the establishment of CSF arrest in the unfertilized egg in meiosis II.

MPF reported in the same article in which Masui and Markert described CSF activity. MPF was regarded as a universal regulator of the $\mathrm{G}_{2} / \mathrm{M}$ transition, and efforts to characterize it lasted many years. MPF was eventually purified in this laboratory and shown to be a heterodimer composed of a catalytic kinase subunit, Cdk1, and a regulatory subunit, cyclin B (Dunphy et al. 1988; Gautier et al. 1988, 1990; Lohka et al. 1988). Similar results were obtained with clam and starfish oocytes (Draetta et al. 1989; Labbe et al. 1989). Importantly, the Cdk1 subunit is homologous to the genetically identified yeast cell cycle control gene, $c d c 2^{+}$, which is now regarded as crucial for the onset of cell division in all cells (Gautier et al. 1988; Nurse 1990).

In the immature oocyte, MPF exists as a complex of Cdc2 (Cdk1) and cyclin B (Cdc2/cyclin B), but is catalytically inactive due to inhibitory phosphorylation of threonine 14 (Thr 14) and tyrosine 15 (Tyr 15) residues by the dual-specificity kinase Myt1 (Fig. 1B; Gautier et al.
1989; Gautier and Maller 1991; Mueller et al. 1995a,b). The steroid hormone PG is now thought to initiate oocyte maturation in nonmammalian vertebrates by binding to a recently identified seven-transmembrane $\mathrm{G}$ protein-coupled receptor (GPCR; Zhu et al. 2003a,b), which also has close homologs in mammals. PG binding to its GPCR inhibits adenylyl cyclase in a GTP-dependent, pertussis toxin-sensitive manner (Finidori-Lepicard et al. 1981; Sadler and Maller 1981; Zhu et al. 2003a), and decreases the level of cAMP within minutes to cause reassociation of the catalytic subunit of cAMP-dependent protein kinase (PKA) with the regulatory subunit (Maller and Krebs 1977; Speaker and Butcher 1977). PKA can inhibit MPF activation even several hours after PG (Maller and Krebs 1977, 1980; Huchon et al. 1981; Rime et al. 1992; Matten et al. 1994). Recent evidence suggests the early inhibition by PKA does not require PKA kinase activity, whereas the late inhibition does (Duckworth et al. 2002; Schmitt and Nebreda 2002). The PG-mediated 
decrease in the level of cAMP is followed by an increase in protein synthesis, and a few hours later germinal vesicle (nuclear) breakdown (GVBD) occurs, as evidenced morphologically by the appearance of a white spot in the center of the pigmented animal pole (Fig. 1A). The ability to monitor the cell cycle phase of oocytes by morphological inspection is an important advantage of this system. In addition to a membrane GPCR, PG also may bind to nuclear receptors present in oocytes and facilitate the process of oocyte maturation, possibly by activation of the MAPK pathway (Bayaa et al. 2000; Tian et al. 2000).

After PG treatment, the new proteins required for maturation are synthesized from maternal messenger mRNA, and $\sim 1 \mathrm{~h}$ preceding GVBD, a "phosphorylation burst" accompanying MPF activation drives progression into M phase (Guerrier et al. 1977; Maller et al. 1977; Doree et al. 1983). Numerous protein kinases in addition to MPF are active during the phosphorylation burst, and the burst occurs downstream of MPF activation. The role of MPF and the phosphorylation burst during maturation is homologous to that in eukaryotic mitoses: promoting chromatin condensation, dissolution of the germinal vesicle (analogous to the somatic cell nuclear envelope breakdown), and bipolar spindle formation (Fig. 1B).

At least two discrete signaling pathways converge in order to mediate the activation of MPF prior to GVBD. One involves the activation of the dual-specificity phosphatase Cdc25C, which itself catalyzes the activation of MPF through direct dephosphorylation of Thr 14 and Tyr 15 on Cdc2 (Fig. 1B; Dunphy and Kumagai 1991; Gautier et al. 1991; Strausfeld et al. 1991; Lee et al. 1992). Cdc25C is activated by the Xenopus polo-like kinase xPlk1 (or Plx1), which itself is activated by upstream kinase kinases such as the Xenopus polo-like kinase kinase, xPlkk1, or related mammalian kinases (Kumagai and Dunphy 1996; Abrieu et al. 1998; Qian et al. 1998, 1999, 2001; Ellinger-Ziegelbauer et al. 2000; Pahlavan et al. 2000; Palmer and Nebreda 2000; Roshak et al. 2000; Jang et al. 2002; Kelm et al. 2002). Evidence supporting $\mathrm{Plx} 1$ as a protein kinase required for Cdc25C activation includes failure to activate $\mathrm{Cdc} 25 \mathrm{C}$ in the absence of $\mathrm{Plx} 1$ protein, and activation of $\mathrm{Cdc} 25 \mathrm{C}$ by expression of a constitutively active form of Plxl in the absence of PG. Phosphorylation by polo-like kinase has also been reported to contribute to nuclear translocation of human Cdc25C in prophase (Toyoshima-Morimoto et al. 2002). In addition, other kinases, such as $\mathrm{p} 38 \gamma$ or $\delta$, may also contribute to activation of Cdc25C (E. Perdiguero and A. Nebreda, pers. comm.). Moreover, Cdc25C may be negatively regulated by PKA-dependent phosphorylation and binding of 14-3-3 proteins prior to activation (Duckworth et al. 2002).

A second signaling pathway, the Mos/MEK/MAPK/ $\mathrm{p} 90^{\text {Rsk }}$ pathway, also operates in the initiation of oocyte maturation (Fig. 1C). The product of the proto-oncogene c-mos is a $39-\mathrm{kD}$ germ cell-specific serine/threonine kinase that was first identified in cells transformed by Moloney murine leukemia virus (Papkoff et al. 1982; Maxwell and Arlinghaus 1985). In oocytes, maternal mos mRNA becomes polyadenylated, and translation begins within 30 min after PG binding (Sagata et al. 1988; Sheets et al. 1994, 1995). The up-regulation of mos translation is a result of complex changes that occur at the 3'-UTR of mos mRNA, which enable its cytoplasmic polyadenylation (for review, see Gebauer and Richter 1997; Mendez and Richter 2001). Mos protein functions as a MAPK kinase kinase (MEKK), important for the activation of the MAPK kinase, MEK1 (Nebreda and Hunt 1993; Posada et al. 1993; Shibuya and Ruderman 1993). MEK1 is a dual-specificity protein kinase that activates MAPK through phosphorylation of threonine-183 and tyrosine-185 within its activation loop (Crews and Erikson 1992; Crews et al. 1992; Kosako et al. 1993). Manipulation of MEK1, MAPK, and $\mathrm{p} 90^{\mathrm{Rsk}}$ in Xenopus oocytes and eggs has contributed substantially to our understanding of the MAPK cascade (for review, see Kosako et al. 1994c), beginning with the discovery that active MAPK could phosphorylate and reactivate the serine/ threonine kinase $\mathrm{p} 90^{\text {Rsk }}$ that had been deactivated by phosphatase treatment (Fig. 1C; Sturgill et al. 1988).

In addition to the xPlkk1/Plx1/Cdc25C pathway, the Mos/MEK/MAPK/p90 Rsk cascade directly aids in the activation and stabilization of MPF activity during the $\mathrm{G}_{2} /$ meiosis I transition. For example, early work by Abrieu and colleagues (1997) suggested a role for MAPK in decreasing the rate and extent of MPF inactivation during the maturation of Xenopus or starfish oocytes. At the molecular level, p90 Rsk has been shown to inhibit Myt1 through direct phosphorylation, thus facilitating Cdc25mediated MPF activation, and entry into meiosis I (Palmer et al. 1998). Other data suggested that Mos might also directly phosphorylate Myt1 (Peter et al. 2002). In addition, during oocyte maturation, cyclin B is phosphorylated at five sites, many of which are contained in its nuclear export sequence (NES; Pines and Hunter 1994; Hagting et al. 1999; Toyoshima-Morimoto et al. 2001). MAPK may contribute to the positive regulation of MPF by stabilizing its nuclear localization through direct phosphorylation of cyclin B on at least two of the sites within its NES.

Exit from meiosis I is associated with degradation of cyclin B to $\sim 50 \%$ of the metaphase level, resulting in partial inactivation of MPF protein kinase activity-yet $M$ phase persists, chromatin remains condensed, the nuclear envelope does not reform, and DNA replication is prevented (Fig. 1A). This partial decrease in the level of cyclin B and MPF activity is merely transient, however, and may not be required for meiotic progression (Peter et al. 2001; Taieb et al. 2001), as shortly after exit from meiosis I, synthesis of cyclin B increases as entry into meiosis II commences (Ledan et al. 2001; Taieb et al. 2001). It is here in the meiosis II oocyte that CSF activity appears and metaphase arrest is established and maintained. On fertilization or parthenogenetic activation, $\mathrm{Ca}^{2+}$ ions are released, anaphase commences, and the fertilized/activated egg advances into early embryonic cell cycles. During this time, cyclin B is fully degraded, and MPF activity declines until entry into $M$ phase of the first mitotic cell cycle. Unlike the rapid decline in MPF activity, however, CSF activity is present for $30-45 \mathrm{~min}$ 
after fertilization before declining (Fig. 2B), but it never reappears in cleaving embryos.

It is evident that CSF acts to prevent MPF inactivation in the egg either by stabilizing MPF directly or by arresting the cell cycle in a metaphase state, which maintains high MPF activity. Two vital questions concerning CSF that still remain to be completely answered are as follows: First, what is the composition and molecular mechanism of action of CSF activity in the vertebrate egg, and second, how is CSF inactivated? The remainder of this article will summarize current understanding of CSF activity, how it is assayed, and the mechanism(s) that establish and maintain CSF arrest. Finally, we will describe the current hypotheses for CSF inactivation upon fertilization or parthenogenetic activation.

\section{Criteria to define CSF and assay of its activity}

Masui and Markert (1971) originally proposed several criteria for a protein, or an activity, to be associated with CSF, including the following: (1) "Emerg[ing] in the oocyte cytoplasm...after progesterone treatment." (2) Causing "the nuclei [to] arrest...in metaphase." The CSF-arrested oocyte is present in a metaphase of meiosis II state. Furthermore, blastomeres injected with egg cytoplasm arrest in metaphase. (3) Being "maintained until the oocyte is activated." (4) Becoming inactivated on egg activation: "Initiation of cleavage [in the embryo] results from the removal of this inhibitory factor from the cytoplasm either by fertilization or by activation of the eggs by other means." This is now known to occur after
Figure 2. Alternate assays for cytostatic factor (CSF). (A) The blastomere injection assay originally performed by Masui and Markert (1971). Cytoplasm from a CSF-arrested egg at metaphase II is injected into one blastomere of a two-cell embryo. The uninjected blastomere continues embryonic cell division normally; however, the blastomere injected with CSF arrests cell division in metaphase with meiotic spindle morphology (i.e., barrel-shaped spindle lacking astral microtubules). Inset shows a normal Xenopus embryo at stage 7 (left), an embryo that had one blastomere injected with Mos protein at the two-cell stage (middle), and a metaphase-arrested spindle from a Mos-arrested blastomere (right). (B) Cycling extract assay. (Top) Fertilization overcomes the CSF-mediated metaphase arrest of mature vertebrate oocytes. This leads to inactivation of MPF and exit from meiosis II (blue), followed by a permanent loss of CSF activity $30-45 \mathrm{~min}$ after fertilization (green). The initiation of embryogenesis is evidenced by cyclical MPF activity indicative of embryonic mitosis and cell cleavage. (Middle) Interphase extracts are prepared in vitro after parthenogenetic activation of CSF-arrested eggs, followed by centrifugal crushing of the eggs 45 min later. Such extracts mimic the early cell cycle transitions of the intact embryo and lack CSF activity (green). (Bottom) Depletion and/or addition of putative CSF components to cycling extracts that are in interphase allows for the determination of whether certain protein(s) or pathway(s) are required for the establishment of CSF arrest at the next $M$ phase, as judged by maintenance of high MPF histone $\mathrm{H} 1$ kinase activity and other biochemical and cytologicalcorrelates. $(C)$ CSF extracts. CSF-arrested extracts are prepared by crushing unfertilized CSF-arrested Xenopus eggs. Such extracts can be used to study whether certain protein(s) or pathway(s) are required for the maintenance of CSF arrest after depleting endogenous activities from the extracts. In addition, these extracts can be released from CSF arrest upon calcium ion addition, causing them to exit meiosis II and rearrest in metaphase of mitosis with high MPF activity due to the reappearance of CSF activity.

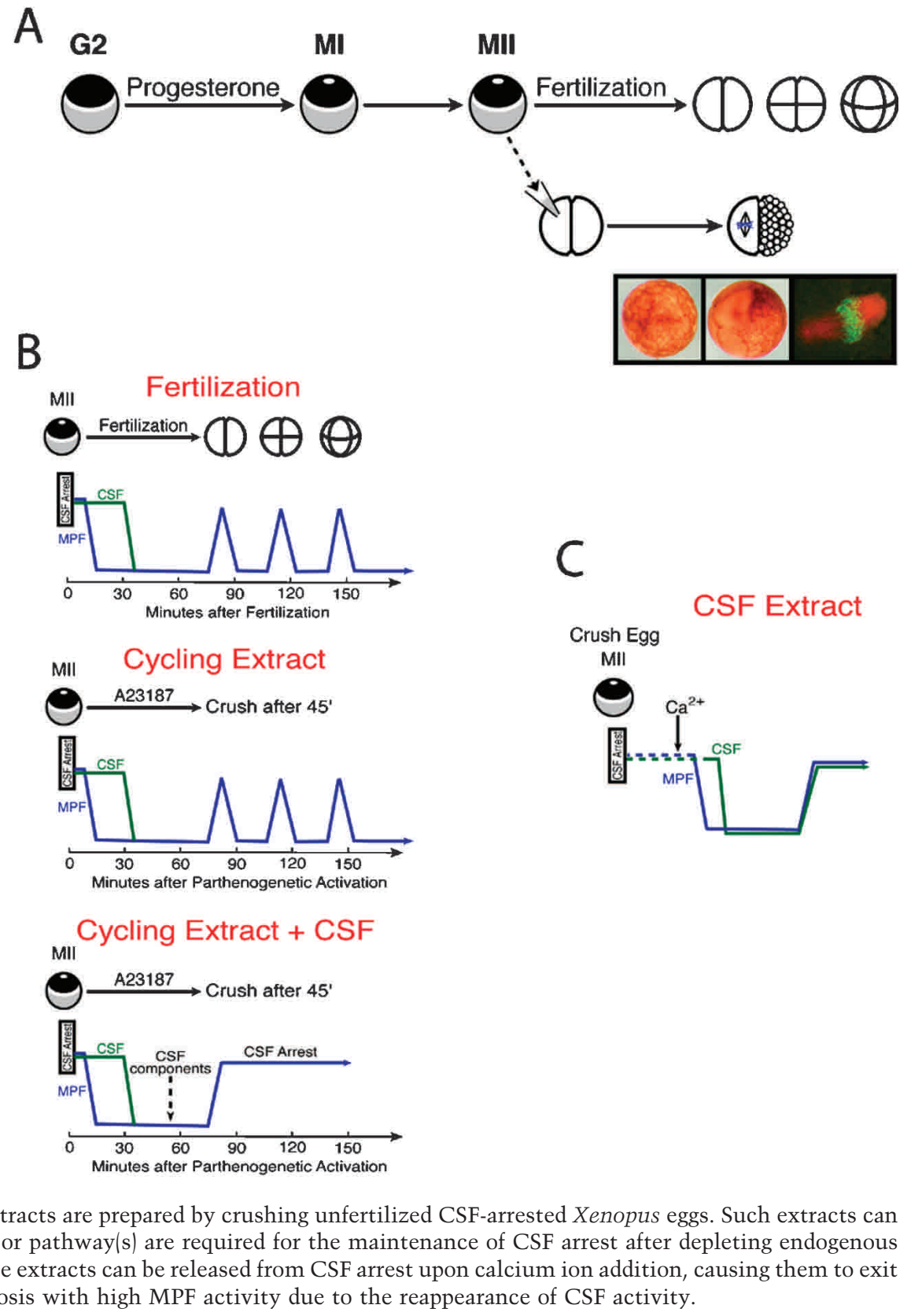


the increase in free calcium that accompanies fertilization or parthenogenetic activation.

To uncover the molecular composition of CSF activity, candidate proteins, or activities, have been subjected to the above criteria using one or more of the following assays: (1) Blastomere injection assay (Fig. 2A). This is the classic experiment performed by Masui and Markert (1971) in their initial discovery of CSF activity, as described previously. By this technique, egg cytoplasm, recombinant protein, or mRNA is injected into one blastomere of a two-cell embryo and scored for ability to arrest cleavage and produce a metaphase spindle with meiotic spindle morphology (i.e., barrel-shaped and lacking centrosomes or prominent astral microtubules). Control blastomeres are injected with buffer, inactive proteins, or irrelevant mRNAs. An additional internal control is that the neighboring uninjected blastomere should continue to divide normally. (2) Extracts prepared from parthenogenetically activated eggs (Fig. 2B). These extracts are prepared 45 min after exit from meiosis II and are thus interphase extracts (Murray and Kirschner 1989; Murray 1991). Because interphase extracts may cycle through multiple rounds of DNA replication and mitosis in vitro, these extracts are also commonly referred to as cycling extracts. Because CSF activity is lost before the extracts are prepared, such extracts can be used to determine whether a specific molecule or pathway is able to reestablish CSF arrest when the extract subsequently cycles into $\mathrm{M}$ phase. In this situation, by adding a molecule to an interphase extract and analyzing the level of MPF (Cdc2) kinase activity, cyclin B protein, and DNA and spindle morphology after initiation of cycling, one can determine whether the extract exits mitosis or arrests at metaphase. (3) Extracts prepared from meiosis II (CSF)-arrested eggs (Fig. 2C). These are more commonly referred to as CSF extracts (Lohka and Maller 1985; Murray 1991). Through the addition of inhibitors, or the depletion of putative proteins important for CSF arrest, one can determine whether a protein or pathway of interest is required for maintenance of the CSF-arrested state. For example, if a protein were important for CSF maintenance, then inhibition or depletion of that protein from the extract should elicit a premature exit from meiosis II, as judged by cyclin B degradation and MPF inactivation. In addition, such extracts can be used to study the $\mathrm{Ca}^{2+}$-dependent inactivation of CSF that occurs on fertilization/activation of the egg.

\section{Molecular composition of CSF}

The early days ...

Long before the term CSF was coined by Masui and Markert, there were many hypotheses about the mechanism of arrest that occurs in mature female gametes of various species. One hypothesis was that there is a lack of communication between nucleus and cytoplasm in the egg, and thus, the egg could not proceed with meiosis until communication was restored-presumably through fertilization (Lillie 1912). Others proposed that arrest may be due to an inhibition of protein synthesis in the egg, based in part on evidence that invertebrate eggs greatly increase protein synthesis after fertilization (Monroy 1965; Winkler et al. 1985). However, vertebrate eggs increase protein synthesis by less than twofold at fertilization. Monroy and colleagues (1965) went so far as to provide evidence for a model by which fertilization brings about the activation of a protease(s). Proteolytic degradation of cyclins and other proteins is now known to be crucial for meiotic exit following fertilization (discussed below).

Pijnacker and Ferwerda (1976) noted that the oocytes of the stick insect Carausius morosus could not become activated in an anaerobic environment. Thus, meiotic arrest was attributed to a lack of oxygen, a condition that may also be present in the oviducts of amphibians. Others proposed nucleotide oligomers or polysaccharides as molecules responsible for meiotic arrest in oocytes of certain marine animals, due to their inhibitory effects on the development of early embryos (Heilbrunn et al. 1954; Menkin 1959; Osanai 1967). Additional evidence implicated a change in intracellular $\mathrm{pH}$ as a requirement for egg activation (Nuccitelli et al. 1981; Webb and Nuccitelli $1981 \mathrm{a}, \mathrm{b}) . \mathrm{CO}_{2}$ was proposed as a molecular inhibitor in eggs because oocytes treated with $\mathrm{CO}_{2}$ had a decreased ability for activation, presumably through acidification of the egg cytoplasm (Brachet 1950). However, the exclusion of $\mathrm{CO}_{2}$ from cultured mature oocytes was insufficient to cause spontaneous activation. In Xenopus, blockade of the increase in intracellular $\mathrm{pH}$ after PG administration has no effect on oocyte maturation (Stith and Maller 1984, 1985).

\section{A role for protein phosphorylation on CSF activity}

Evidence that CSF arrest might be due to the activity of a kinase, or protein phosphorylation, began to accumulate after Masui and Markert's (1971) initial observations of CSF and MPF activities. The possibility that CSF arrest involved changes in phosphorylation was suggested by the discovery that MPF activity was stabilized by $\beta$-glycerophosphate and caused a "phosphorylation burst" in injected oocytes (Guerrier et al. 1977; Maller et al. 1977; Doree et al. 1983). In 1977 it was reported that CSF activity could be stabilized in egg extracts that were prepared in the presence of magnesium ions, whereas the addition of EDTA to the extraction medium, or to soluble extracts, was inhibitory to CSF activity (Meyerhof and Masui 1977). The addition of ATP and NaF to soluble egg extracts stabilized and even enhanced CSF activity in the blastomere injection assay, providing further evidence for a role of protein phosphorylation in maintaining CSF arrest in the egg (Shibuya and Masui 1988). Likewise, as seen with studies on MPF, the addition of $\gamma$-S-ATP to the extracts had a similar effect on enhancing their ability to cause metaphase arrest in injected blastomeres (Shibuya and Masui 1988; Yamashita and Maller 1990). They also reported stabilization of CSF activity in Xenopus egg extracts prepared in the presence of $\beta$-glycerophosphate (Moses and Masui 1990). NaF and 
$\beta$-glycerophosphate may inhibit the activity of protein phosphatases, and thiophosphorylated proteins are often nonhydrolyzable by protein phosphatases. Thus phosphoproteins are presumably stabilized in an active state. Lastly, they found that CSF activity was lost when the egg extracts were incubated with proteases or warmed to $25^{\circ} \mathrm{C}$ for $2 \mathrm{~h}$ or more (Shibuya and Masui 1989). Thus, during the 17 years after its discovery, evidence had accumulated to suggest a major factor important for the establishment and maintenance of CSF arrest was likely to be a protein kinase found in its active form in meiosis II oocytes.

\section{Identification of Mos-dependent CSF arrest}

During this time, a large body of evidence was also accumulating concerning the nature of the cellular homo$\log$ of the viral oncogene $\mathrm{v}$-mos. Research from a variety of organisms demonstrated that c-mos mRNA is highly expressed in vertebrate gonadal tissues, and Mos is synthesized to a high level during germ cell maturation (Propst and Vande Woude 1985; Goldman et al. 1987; Mutter and Wolgemuth 1987; Propst et al. 1987; Schmidt et al. 1988). Mos was also found to have a role in MPF activation during entry into meiosis I and throughout oocyte maturation (Propst and Vande Woude 1985; Goldman et al. 1987; Mutter and Wolgemuth 1987; Propst et al. 1987; Keshet et al. 1988; Mutter et al. 1988; Sagata et al. 1988, 1989a; Schmidt et al. 1988; Paules et al. 1989). In fact, oocytes injected with synthetic mos mRNA activated MPF and initiated GVBD in the absence of PG stimulation (Sagata et al. 1989a). Microinjection of recombinant Mos protein into immature oocytes also activated MPF and precipitated entry into meiosis I in the absence of hormonal stimulation (Yew et al. 1992). Similar effects on GVBD without PG were subsequently observed with activated downstream components of the Mos signaling pathway, including MEK1, MAPK, and p90 Rsk (Gotoh et al. 1995; Haccard et al. 1995; Huang et al. 1995; Gross et al. 2001). Thus, Mos was tentatively classified as the "initiator" of oocyte maturation (Sagata et al. 1989a). Recently, this concept has been questioned by evidence that GVBD in isolated oocytes can be achieved in the absence of Mos, or the MAPK pathway (Fisher et al. 1999; Gross et al. 2000; Dupre et al. 2002), and other proteins, notably the Cdc2 activator protein RINGO, are reported to be synthesized during meiosis and are sufficient for initiating GVBD (Ferby et al. 1999). Moreover, oocytes from mice that are homozygously deleted for the mos gene are able to undergo GVBD normally (Colledge et al. 1994; Hashimoto et al. 1994).

The Mos connection to the molecular nature of CSF arrest at the end of meiosis II was revealed in a seminal paper by Sagata and colleagues (1989b). They used both gain-of-function and loss-of-function approaches to establish that Mos is sufficient for CSF activity. In the first experiment, mos mRNA stabilized MPF in the blastomere injection assay originally performed by Masui using egg cytoplasm. Blastomeres injected with mos mRNA arrested after one or two divisions, depending on the concentration of mRNA, and arrested blastomeres contained condensed chromatin indicative of metaphase. The sharp dose dependence for Mos-induced arrest suggested that a threshold amount of Mos protein is necessary for the arrest. Indeed, some evidence suggests that the $\beta$ subunit of casein kinase II acts as an inhibitor of Mos and creates a "threshold" requirement for Mos functions (Chen and Cooper 1997; Chen et al. 1997). In the second experiment, Sagata and colleagues (1989b) immunodepleted Mos protein from CSF extracts, and the depleted extract was incapable of causing cleavage arrest in the embryo, whereas mock-depleted extracts arrested $97 \%$ of the blastomeres that were injected. In addition, polyclonal antibodies against Mos neutralized Mos activity in the extracts, and prevented the extracts from arresting injected blastomeres.

As described previously, the criteria for a protein, or an activity, to be classified as a component of CSF specified that it would appear during oocyte maturation, induce metaphase arrest, be maintained until fertilization/activation, and then become inactivated (Masui 2000). The evidence provided by Sagata and others certainly met the first three requirements. Maternal mos mRNA is present in the resting oocyte, and Mos protein is synthesized after PG stimulation as a consequence of cytoplasmic polyadenylation of mos mRNA (Sagata et al. 1988; Gebauer and Richter 1997). Therefore, the protein kinase activity of Mos during oocyte maturation as witnessed by the downstream activation of the MAPK pathway would fit the pattern predicted for a component of CSF. In addition, Sagata et al. (1989b) clearly showed that the chromatin in arrested blastomeres is arrested with metaphase morphology. Lastly, Mos protein is maintained in the egg during CSF arrest, because Sagata was able to immunodeplete, or neutralize, the endogenous Mos protein prior to blastomere injection (Sagata et al. 1989b). The question that remained was whether Mos is downregulated on fertilization of the egg.

\section{$\mathrm{Ca}^{2+}$ release and $\mathrm{Mos}$ regulation}

Fertilization of the vertebrate egg causes a wave of calcium ions to spread throughout the cell from the site of sperm entry (Kubota et al. 1987). The resultant rapid depolarization of the plasma membrane constitutes the primary block to polyspermy (Wyrick et al. 1974; Wolf et al. 1976). The transient increase in intracellular $\mathrm{Ca}^{2+}$ serves to "activate" the egg. Egg activation initiates breakdown of the cortical granules on the plasma membrane, producing a hardening of the zona pellucida, which functions as a secondary block to further sperm fusion (for review, see Runft et al. 2002). As an alternative to fertilization-induced activation, eggs may be parthenogenetically activated by use of the calcium ionophore (A23187) to artificially increase the intracellular $\mathrm{Ca}^{2+}$ concentration, or by injection of calcium directly into the egg cytosol (Schroeder and Strickland 1974; Steinhardt et al. 1974; Belanger and Schuetz 1975; Schuetz 1975; Masui et al. 1977; Fulton and Whittingham 1978). Conversely, in some species microinjection of EGTA into the egg cyto- 
plasm prevents activation upon fertilization (Zucker and Steinhardt 1978).

The increase of free $\mathrm{Ca}^{2+}$ within the egg cytosol also causes the resumption of meiosis II. The egg is released from the CSF-mediated metaphase arrest and progresses from metaphase II to anaphase II, followed by the emission of the second polar body (cytokinesis) and entry into embryonic cell cycles. Meyerhof and Masui (1977) used the blastomere injection assay to show that egg extracts prepared in the presence of $5 \mathrm{mM} \mathrm{CaCl}_{2}$ lost the ability to arrest injected blastomeres within an hour of extraction, whereas addition of EGTA to the extracts stabilized CSF activity. Thus, CSF activity present in the egg cytosol is lost on metaphase II release and is sensitive to an increase in $\mathrm{Ca}^{2+}$. CSF activity, therefore, is maintained in the egg until fertilization/activation causes an increase in the intracellular free $\mathrm{Ca}^{2+}$ concentration.

For Mos protein to meet the full criteria expected of a component of CSF activity, it would also need to be inactivated upon fertilization/activation of the egg in response to an elevated intracellular $\mathrm{Ca}^{2+}$ concentration. Early studies suggested that Mos protein is degraded by a calcium-dependent cysteine protease, calpain, after egg activation by the calcium ionophore A23187 (Watanabe et al. 1989). However, it was later shown that a transient, physiologically relevant increase in free $\mathrm{Ca}^{2+}$, as occurs during fertilization, does not activate calpain (Lorca et al. 1991). Precise time-course experiments later showed that Mos protein is dephosphorylated within $20 \mathrm{~min}$ of egg activation, followed by its degradation (Watanabe et al. 1991). MPF activity and the level of cyclin B protein were completely diminished within the first 10 min after activation, thus preceding the degradation of Mos (Fig. 2B). Additional evidence suggested that the degradation of Mos protein is due to polyubiquitination of Lys 34, followed by degradation by the $26 \mathrm{~S}$ proteasome (Ishida et al. 1993; Nishizawa et al. 1992, 1993). However, if Mos is phosphorylated on Ser 3, as occurs after GVBD in Xenopus oocytes, the ubiquitin-mediated degradation machinery is unable to recognize Mos protein (Sheng et al. 2002). Recent data provide evidence for an MPF-mediated phosphorylation of Ser 3 on Mos in vitro, which produces an electrophoretic mobility shift, as well as a phosphopeptide map, similar to those seen in vivo (Freeman et al. 1992; Castro et al. 2001). Thus, upon egg activation cyclin B is degraded, and the concomitant loss of MPF activity presumably results in the dephosphorylation and subsequent degradation of Mos protein.

Finally, in addition to Mos protein degradation, translation from maternal mos mRNA is arrested after egg activation as a consequence of deadenylation downstream of important 3' UTR sequences (Ueno and Sagata 2002). Thus, mos mRNA is polyadenylated after PG stimulation of the oocyte. Mos protein kinase activity emerges and is maintained until fertilization, when the increase in intracellular $\mathrm{Ca}^{2+}$ initiates the dephosphorylation and degradation of Mos protein, in conjunction with the deadenylation of mos mRNA. Hence, Mos satisfies all of the criteria necessary to be characterized as a component of CSF activity.
What lies downstream of Mos?

Virtually all of the p42 MAPK present in the immature Xenopus oocyte becomes tyrosine phosphorylated and activated after PG treatment (Ferrell et al. 1991; Gotoh et al. 1991; Jessus et al. 1991; Posada et al. 1991; Posada and Cooper 1992). MAPK remains active throughout oocyte maturation and is inactivated after fertilization/activation of the mature oocyte (Fig. 1A). Mos protein is responsible for the activation of MAPK during oocyte maturation (Nebreda and Hunt 1993; Posada et al. 1993; Shibuya and Ruderman 1993). This suggested that MAPK might mediate some of the actions of Mos during oocyte maturation.

During this time, an upstream protein kinase was identified that was able to phosphorylate both threonine and tyrosine residues on the activation loop of MAPK (Ahn et al. 1991; Crews and Erikson 1992; Crews et al. 1992; Nakielny et al. 1992; Kosako et al. 1993). This protein, termed MAPK/Erk kinase (MEK1), converted unphosphorylated MAPK into an active diphosphorylated protein similar to what occurs in vivo downstream of growth factors or phorbol esters in somatic cells. MEK1 was also identified as the upstream activator of MAPK during Xenopus oocyte maturation (Kosako et al. 1992; Matsuda et al. 1992; Tobe et al. 1992). Microinjection of MEK1 protein into immature oocytes resulted in the immediate activation of MAPK (Matsuda et al. 1992; Gotoh et al. 1995). Inhibition of MEK1 with the specific MEK inhibitor PD98059, or by microinjection of antiMEK antibodies, prevented PG-induced oocyte maturation (Kosako et al. 1994b; Cross and Smythe 1998).

Mos activates MEK1 during oocyte maturation by phosphorylating two conserved serine residues: Ser 218 and Ser 222 (Posada et al. 1993; Huang et al. 1995). Mutation of either serine to an aspartic acid residue activates MEK1 10- to 50-fold, and mutation of both serine residues to aspartic acid activates MEK1 >6,000-fold, resulting in a constitutively active form of the kinase (Mansour et al. 1994; Huang et al. 1995). Lastly, one of the functions of Mos is as a putative initiator of oocyte maturation (Sagata et al. 1989a; Gotoh et al. 1995). Constitutively active MEK1 was able to fully activate MAPK and initiate Xenopus oocyte maturation in the absence of Mos (Huang et al. 1995), although it was unable to fully activate MAPK or cause GVBD in oocytes from $\mathrm{mos}^{-/-}$mice (Verlhac et al. 2000). Expression of a specific MAPK phosphatase, Mkp1/CL100, in immature oocytes blocked MAPK activation after PG treatment and prevented oocyte maturation (Gotoh et al. 1995). This laboratory generated an active, phosphatase-resistant form of recombinant MAPK by thiophosphorylation of MAPK with $\gamma$-S-ATP and showed that thiophosphorylated MAPK could induce oocyte maturation in the absence of PG or Mos (Haccard et al. 1995). Taken together, these results indicate that at least in Xenopus, MAPK is the sole effector of Mos downstream of MEK1 activation that is required for the induction of oocyte maturation. Thus, a clear Mos/MEK1/MAPK signaling pathway had been identified and shown to be sufficient for initiating Xenopus oocyte maturation. 
Mos exerts CSF activity by activating the MAPK pathway

Given that the ability of Mos to cause GVBD is due to its activation of the MAPK pathway, it was important to test whether MEK1 or MAPK may also mediate the establishment of metaphase arrest by Mos during meiosis II entry in the egg. Attempts at injecting purified MAPK from unfertilized eggs into one blastomere of a two-cell embryo were unsuccessful in causing cleavage arrest. One reason for this is that MAPK is dephosphorylated and inactivated by specific phosphatases that become active after fertilization of the egg (Ferrell et al. 1991; Sarcevic et al. 1993). However, injection of phosphataseresistant thiophosphorylated wild-type, but not kinase dead, MAPK into one blastomere of a two-cell embryo arrested the injected blastomere in metaphase (Haccard et al. 1993). The ability of Mos to cause CSF arrest in the egg was thus due to the protein kinase activity of MAPK. Kosako and colleagues subsequently confirmed a role for MEK1 in mediating CSF activity directly downstream of Mos protein, and in the activation of MAPK for this arrest (Kosako et al. 1994a). By using anti-MEK1 antibody, they were able to show an inhibition of MAPK activation by recombinant Mos protein in extracts derived from immature oocytes. In addition, co-injection of antiMEK1 antibody and recombinant Mos protein prevented metaphase arrest in the injected blastomere of a two-cell embryo, whereas recombinant Mos protein and control antibody were sufficient for the arrest. Furthermore, in cells derived from the anti-MEK1 antibody/Mos injection, MAPK was never activated. Thus, the effect of Mos in the establishment of CSF arrest in meiosis II oocytes must operate solely through the downstream kinase MEK1 to cause the MAPK-mediated arrest. Subsequent studies in cycling egg extracts also showed that Mosdependent activation of MAPK could stabilize M phase (Chau and Shibuya 1998).

During Xenopus oocyte maturation, the activation of the $90-\mathrm{kD}$ ribosomal protein S6 kinase (p90 Rsk) closely parallels the activation of MAPK (Erikson and Maller 1989|. In this system, as well as many others, it has been shown that MAPK directly phosphorylates and activates p90 Rsk (Sturgill et al. 1988; for review, see Frodin and Gammeltoft 1999|. Cloning of Xenopus and mammalian p90 $0^{\text {Rsk }}$ proteins has revealed that it is composed of two complete kinase domains in the $\mathrm{N}$ - and C-terminal halves of the protein. Three different $\mathrm{p} 90^{\mathrm{Rsk}}$ isoforms, termed Rsk1, Rsk2, and Rsk3, have been identified in mammals, and all three isoforms have the two-kinase domain structure. The C-terminal kinase domain is activated by MAPK and then autophosphorylates the linker region between the two kinase domains to promote activation of the $\mathrm{N}$-terminal kinase domain by PDK-1, enabling the phosphorylation of exogenous substrates (for review, see Frodin and Gammeltoft 1999). In Xenopus only Rsk1 and Rsk2 have been identified, and both are present and active throughout oocyte maturation (Erikson and Maller 1985, 1989; Jones et al. 1988; Bhatt and Ferrell 2000).
As has been discussed above concerning the gain-offunction forms of MEK1 and MAPK, a gain-of-function mutant of $\mathrm{p} 90^{\text {Rsk }}$ is also capable of initiating oocyte maturation in the absence of PG (Gross et al. 2001). In addition, mRNA encoding a constitutively active mutant of Rsk1 (CA-Rsk) composed of only the N-terminal kinase domain had CSF activity sufficient to arrest the blastomere of a two-cell embryo in metaphase (Gross et al. 1999). This arrest occurred at a concentration of Rsk activity lower than that present in unfertilized eggs. Biochemical analysis of injected blastomeres revealed that the endogenous MAPK and $\mathrm{p} 90^{\text {Rsk }}$ proteins were not activated by CA-Rsk, indicating that the only substrate of MAPK needed for CSF arrest is $\mathrm{p} 90^{\mathrm{Rsk}}$. CSF arrest also occurs with an additional gain-of-function mutant protein of Rsk1 that contains both kinase domains and has enhanced specific activity (FA-Rsk; Gross et al. 2001). Loss-of-function experiments with Xenopus $\mathrm{p} 90^{\mathrm{Rsk}}$ protein have also provided evidence for a role for $\mathrm{p} 90^{\mathrm{Rsk}}$ in the establishment of CSF arrest downstream of the Mos/ MEK1/MAPK pathway. Bhatt and Ferrell (1999) showed that recombinant Mos protein was unable to establish CSF activity in interphase extracts after complete immunodepletion of endogenous $\mathrm{p} 90^{\text {Rsk }}$. They were able to rescue Mos-induced arrest through the addition of recombinant wild-type, but not kinase dead, Rsk1 or Rsk2 to the immunodepleted extract while in interphase. p $90^{\text {Rsk }}$ is thus both necessary and sufficient for CSF arrest.

Thus far, the molecular nature of CSF activity appears to be downstream of only one clearly defined signal transduction pathway, the Mos/MEK/MAPK/p90 Rsk pathway. Each member of the pathway is synthesized and/or activated upon PG-mediated induction of oocyte maturation, and an active form of each is sufficient to induce oocyte maturation on its own. Moreover, each kinase depends only on downstream elements of the pathway for the CSF-mediated establishment of meiotic metaphase arrest. Mos protein is degraded, and mos mRNA is deadenylated after fertilization/activation, providing one mechanism to deactivate the MAPK pathway. Unlike Mos, however, MEK1, MAPK, and p90 Rsk are not degraded after fertilization, and translation from their individual mRNAs is not inhibited. However, MEK1, MAPK, and $\mathrm{p} 90^{\text {Rsk }}$ are inactivated by dephosphorylation shortly after the increase in free $\mathrm{Ca}^{2+}$ that occurs during fertilization/activation, and MAPK activity remains low during the cell cycles of early embryos (Ferrell et al. 1991; Hartley et al. 1994). This suggests that in Xenopus Mos is the only MAPKKK (MEKK) operative during oocyte maturation and early embryonic cell cycles.

\section{CSF arrest and the spindle checkpoint}

The cell cycle of somatic cells is comprised of "checkpoints" that ensure the complete replication of the genome in S phase and equal segregation of chromosomes in $M$ phase. The spindle assembly/kinetochore attachment checkpoint arrests cells undergoing mitosis in 
metaphase until the chromosomes become aligned on the metaphase plate and the kinetochores of each chromatid pair have attached to or are under tension with mitotic spindle microtubules (for review, see Burke 2000; Shah and Cleveland 2000; Wassmann and Benezra 2001; Millband et al. 2002; Musacchio and Hardwick 2002). Once the spindle has been correctly assembled, the checkpoint arrest is relieved, the cells enter anaphase, and the genome is equally segregated to opposite spindle poles to form two karyotypically identical daughter cells. Clearly, if mitosis were to proceed before each sister chromatid was attached to the proper spindle, the resulting daughter cells could obtain too little or too much genetic information-a defect termed aneuploidy. Unequal segregation of the genome can produce genomic instability, and result in cell death or unregulated cell growth.

During chromosome condensation, a multiple-protein complex, termed the kinetochore, congregates at the centromeric region of each chromatid. Not only are kinetochores important for the attachment of spindle microtubules during prometaphase/metaphase, they are also central in signaling the spindle checkpoint. Chromosomes with kinetochores that are unattached to the mitotic/meiotic spindle signal through the spindle assembly checkpoint pathway to stop mitotic/meiotic progression, and arrest in metaphase until correction is made. In fact, a single unattached and unaligned kinetochore is sufficient to activate the checkpoint and initiate the arrest (Li and Nicklas 1995; Rieder et al. 1995).

The spindle assembly checkpoint is composed of multiple proteins that were originally identified in budding yeast mutants that had lost the ability to arrest in metaphase after the addition of microtubule poisons (Hoyt et al. 1991; Li and Murray 1991). The mad1-3 (mitotic arrest defective) and bub1-3 (budding uninhibited by benzimidazole) gene products were found to be critical for metaphase arrest in response to a disrupted spindle. In addition, the mps1 (monopolar spindle $\underline{1}$ ) gene from budding yeast has been identified more recently to have a role in the spindle assembly checkpoint, because mps1-1 mutants of Saccharomyces cerevisiae fail to arrest in metaphase in response to an unduplicated spindle pole body (SPB; yeast equivalent of a centrosome), which results in a disrupted spindle (Winey et al. 1991; Weiss and Winey 1996).

Mad1, Mad2, Mad3/BubR1, Bub1, Bub3, and Mps1 are all conserved in vertebrates and have been shown to be important for activation of the spindle assembly checkpoint in vertebrate cells and in Xenopus egg extracts (Chen et al. 1996, 1998; Burke 2000; Gardner and Burke 2000; Abrieu et al. 2001; Schwab et al. 2001; Sharp-Baker and Chen 2001; Chen 2002; Stucke et al. 2002). In fact, mutant forms of many of these genes have been found in certain human cancers (for review, see McDonald and El-Deiry 2001; Fagin 2002). On the other hand, a Bub2 homolog has not been identified in vertebrates. It does not function in the spindle assembly checkpoint but may be important for regulating the position of the spindle independently of these other proteins (for review, see Taylor 1999; Burke 2000; Gardner and Burke 2000).

Work by Minshull and colleagues (1994) nearly a decade ago identified a role for MAPK in the spindle assembly checkpoint using Xenopus cycling egg extracts. These extracts exhibit only $S$ and $M$ phases and lack most cell cycle checkpoints unless the DNA/cytoplasmic ratio is markedly increased (Dasso and Newport 1990; Dasso et al. 1992). These investigators found that nocodazole could activate the spindle checkpoint and block anaphase in cycling egg extracts that had been supplemented with $>9,000$ sperm nuclei/ $\mu \mathrm{L}$ of extract. More typically, in this laboratory 14,000 nuclei/ $\mu \mathrm{L}$ are required for a nocodazole-dependent arrest. Such extracts are prepared 30-45 min after parthenogenetic activation, ensuring that Mos protein and mRNA have been degraded and that CSF activity is no longer present (Fig. 1B). However, if the dual specificity MAPK phosphatase MKP-1/CL100 was added to the extracts while in interphase, the extracts failed to arrest in the next mitosis and returned to interphase like non-nocodazoletreated control extracts. Minshull et al. (1994) also found that addition of MKP-1/CL100 to the extracts after the arrest had been established caused release from the arrest and induced entry into interphase. It was later shown that immunodepletion of endogenous MAPK from interphase extracts prevented the establishment of the spindle checkpoint as well, and the checkpoint could be rescued by adding back recombinant MAPK (Takenaka et al. 1997; Wang et al. 1997). Thus, MAPK is important for the establishment and maintenance of the spindle assembly checkpoint after microtubule depolymerization in egg extracts. Nocodazole treatment of the Xenopus tadpole cell line (XTC) also causes activation of the spindle assembly checkpoint and metaphase arrest (Wang et al. 1997). Microinjection of MKP-1/CL100 into nocodazole-treated XTC cells abolished this arrest, similar to the case in egg extracts. However, co-injection of MKP-1/CL100, and a constitutively active form of recombinant human MEK1 protein could restore the spindle assembly checkpoint in these cells. Thus, MAPK activity was found to be important for the spindle assembly checkpoint in vertebrate cells. Signaling the spindle checkpoint: the importance
of the kinetochore

The Mad1, Mad2, Mad3/BubR1, Bub1, Bub3, and Mps1 proteins are localized on kinetochores in early prophase and remain on unattached kinetochores until metaphase/early anaphase, when all kinetochores have attached to microtubules and become aligned at the metaphase plate (Chen et al. 1996; Basu et al. 1998; Taylor et al. 1998; Schwab et al. 2001; Sharp-Baker and Chen 2001; Chen 2002; Chung and Chen 2002). Retention of these proteins on kinetochores after treatment of the cell with drugs that depolymerize microtubules, or microinjection of antibodies against kinetochore proteins such that microtubules are unable to bind, correlates with the block to anaphase (Bernat et al. 1990; Yen et al. 1991; Tomkiel 
et al. 1994). The binding of microtubules and/or the generation of tension at the kinetochore is thought to cause the displacement of these proteins from the kinetochore during metaphase in normal cells. This displacement is thought to be a probable mechanism whereby the spindle assembly checkpoint signal becomes inactivated.

In vertebrate cells, MAPK was found to localize to the mitotic spindle during prometaphase and metaphase in XTC cells but was undetectable in anaphase (Wang et al. 1997). By using various mammalian epithelial cell lines, several laboratories have used phosphorylation site-specific antibodies for MEK1 or MAPK to observe the active forms of these enzymes in the nucleus during the early stages of mitosis (Shapiro et al. 1998; Zecevic et al. 1998). Active MAPK, which accounts for only a minute fraction of the total MAPK present in the cell, was found on spindle poles and kinetochores during prophase and prometaphase, with slightly decreased staining on aligned chromosomes in metaphase. However, the staining of active MAPK on kinetochores of metaphase chromosomes was greatly enhanced after activation of the spindle assembly checkpoint by the microtubule depolymerizing drug nocodazole, and expression of MAPK phosphatase was able to block nocodazole-induced arrest.

Gorbsky and Ricketts (1993) have used a monoclonal antibody (Cyert et al. 1988) specific for the phosphorylated forms of nuclear antigens. This antibody $(3 \mathrm{~F} 3 / 2)$ is particularly efficient at staining kinetochore phosphoepitopes under conditions that activate the spindle assembly checkpoint-chromosome misalignment or detachment from the mitotic spindle. Attachment of microtubules to kinetochores results in the loss of $3 \mathrm{~F} 3 / 2$ signal, suggesting that these phosphoantigens become displaced and/or dephosphorylated and may be important for signaling the spindle assembly checkpoint-mediated metaphase arrest. Although the exact epitope recognized by the $3 \mathrm{~F} 3 / 2$ antibody is unknown, Shapiro and colleagues (1998) were able to show co-localization of active MAPK and 3F3/2 immunoreactivity on kinetochores in normal cells, and enhanced immuonreactivity was evident in cells arrested by nocodazole or on misaligned chromosomes in untreated cells. Perfusion of these cells with the phosphatase PP2A decreased 3F3/2 staining, but this could be rescued by readdition of the phosphatase inhibitor microcystin, active MAPK, and MgATP. This suggests that 3F3/2 epitopes may be directly or indirectly phosphorylated in response to MAPK localization at the kinetochore.

The microtubule motor protein CENP-E (centromerebinding protein $\underline{E}$ ) may be one of many substrates for active MAPK on kinetochores, because it was shown to co-localize with active MAPK immunoreactivity on chromosomes and to be co-immunoprecipitated with active or inactive MAPK from interphase and mitotic cells (Zecevic et al. 1998). In addition, MAPK is able to phosphorylate CENP-E on residues in vitro that are known to regulate its ability to bind microtubules. This suggests that one of the functions of active MAPK on kineto- chores during mitosis is to regulate the interaction of CENP-E with microtubules and monitor mitotic progression. Inasmuch as CENP-E is essential for the spindle assembly checkpoint (Abrieu et al. 2000), CENP-E is a possible target for CSF arrest, because CSFarrested spindles in both Xenopus and mouse eggs have been reported to have certain CENP-E epitopes masked compared with spindles in meiosis I or mitosis (Duesbery et al. 1997). In addition, these epitopes are unmasked in oocytes from $\mathrm{mos}^{-/-}$mice, suggesting that CENP-E is phosphorylated downstream of Mos activity during meiosis II. However, CSF arrest can be recapitulated in vitro by using unfertilized egg extracts which lack added DNA, and therefore kinetochores, suggesting that although CENP-E may be a target of MAPK in the metaphase-arrested egg, it may not be required for the cell cycle arrest. Whether it regulates the unusual stability of the metaphase II spindle is an attractive possibility.

\section{The 'wait anaphase' signal}

The spindle assembly checkpoint maintains the metaphase-arrested state of the cell by inhibiting the degradation of key proteins important for mitotic/meiotic maintenance. For example, the Cohesin protein complex that "glues" sister chromatids together during mitosis/ meiosis is destroyed during entry into anaphase, thus allowing the separation and subsequent segregation of sister chromosomes to opposite spindle poles (for review, see Nasmyth et al. 2000; Uhlmann 2001; Campbell and Cohen-Fix 2002). The Cohesin subunit Sccl is destroyed by the protease Separase in early anaphase to initiate this process (Uhlmann et al. 1999). Separase is kept inactive until anaphase through the direct binding of the protein Securin (Ciosk et al. 1998; Hornig et al. 2002). Upon metaphase exit Securin is polyubiquitinated and then degraded by the $26 \mathrm{~S}$ proteasome. In addition, mitotic/ meiotic cyclins (A- and B-type), proteins involved in the activation of Cdc2 during entry into mitosis/meiosis, must be ubiquitinated and degraded in order to exit $M$ phase (Evans et al. 1983; Glotzer et al. 1991; Luca et al. 1991). The spindle assembly checkpoint operates to prevent anaphase and the inactivation of Cdc2 by inhibiting the polyubiquitination and degradation of Securin and cyclin B during metaphase arrest. Thus, the ubiquitination of Securins, cyclin subunits, and possibly other proteins is required for anaphase and exit from mitosis, but the spindle assembly checkpoint signals generated from unattached kinetochores prevent this activity.

The ultimate target of the spindle assembly checkpoint pathway is the anaphase-promoting complex or cyclosome (APC/C). The APC/C holoenzyme functions as an E3 ubiquitin ligase that directly ubiquitinates cyclin $\mathrm{B}$ and Securin proteins, among others, to promote anaphase entry. The APC/C is composed of $\sim 11$ core protein subunits and is activated through the binding of an activator/specificity factor, either Cdc20/Fizzy/p55 ${ }^{\mathrm{CDC}}$ or Cdh1/Fizzy-related/Hct1 (for review, see Harper et al. 2002). Cdc20 is required for the ubiquitin ligase activity 
of the APC/C in mitotic and meiotic cell cycles, whereas Cdh1/Fizzy-related/Hct1 is necessary for APC/C activity in late mitosis and G1 phase. Cdc20 or Cdh1 bound to the APC/C not only activate its ubiquitin ligase activity but also regulate the substrate-specificity of the APC/C. In fact, these activator/specificity factors have recently been found to recruit substrates to the APC/C for degradation. Substrates for the APC ${ }^{\mathrm{Cdc} 20}$ complex generally contain a primary amino acid sequence termed the destruction box (D-box), RxxLxxxxN, whereas APC Cdh1 substrates generally contain a KEN box motif, KENxxxN (Glotzer et al. 1991; King et al. 1996; Pfleger and Kirschner 2000). However, many APC/C substrates contain both sequences, and some investigators have provided evidence suggesting that certain proteins must have both sequences for efficient degradation (Petersen et al. 2000, Burton and Solomon 2001; Hendrickson et al. 2001; Jacobs et al. 2001; Zur and Brandies 2001). Some APC ${ }^{C d h 1}$-dependent substrates may require additional motifs (Castro et al. 2002; Littlepage and Ruderman 2002).

The spindle assembly checkpoint arrests cells in metaphase by ultimately affecting the binding of either Mad2 or Mad3/BubR1 to Cdc20 or Cdh1 (Li et al. 1997; Hwang et al. 1998; Chan et al. 1999; Fang 2002; for review, see Musacchio and Hardwick 2002). The binding of these proteins inhibits the ability of Cdc20 to activate the APC-mediated polyubiquitination of cyclins, Securins, and possibly other proteins. At least a portion of the $\mathrm{APC} / \mathrm{C}$ is found localized on the kinetochore and mitotic spindle, suggesting it may play a role in the localized ubiquitination of target proteins (Tugendreich et al. 1995; Clute and Pines 1999; Huang and Raff 1999). The core anaphase-promoting complex and its activator, Cdc20, are present in the Xenopus oocyte and function during oocyte maturation. However, the APC activator Cdh1 is not present in the oocyte and does not appear until after the mid-blastula transition (MBT) during embryogenesis-when $\mathrm{G}_{1}$ phases first appear (Lorca et al. 1998). The Mad1, Mad2, Mad3/BubR1, Bub1, and Bub3 proteins are also present in oocytes, and some of these proteins (e.g., Bub1) are on kinetochores and become activated during oocyte maturation (Schwab et al. 2001; Sharp-Baker and Chen 2001; Chen 2002). Lastly, the MAPK pathway becomes active during early prophase of meiosis I and remains active until fertilization. Thus, MAPK, the spindle assembly checkpoint proteins, and the APC are all present in the egg.

\section{CSF arrest by APC/C inhibition}

Using metaphase arrest that occurs after spindle disruption in somatic cells as a model, recent efforts have investigated whether CSF arrest involves an inhibition of the $\mathrm{APC} / \mathrm{C}$, and whether this is dependent on the activities of some, or all, of the proteins involved in the spindle assembly checkpoint in yeast and somatic cells. Evidence against such an hypothesis includes the fact that the CSF-arrested oocyte has an intact spindle with chromosomes that are perfectly aligned on the metaphase plate. Presumably, the kinetochores of each sister chromatid must be attached to the meiotic spindle for the observed proper positioning of the chromosomes to occur. Therefore, if no spindle disruption has occurred, it seems unlikely that the spindle checkpoint mechanism could be functioning in CSF arrest. In addition, both the formation and inactivation of CSF arrest are unaffected by disruption of the spindle with nocodazole. Additional evidence against a spindle checkpoint mechanism for CSF arrest includes the absence of genetic evidence in budding yeast for any involvement of MAPK in the checkpoint, and the absence of a $\mathrm{p} 90^{\mathrm{Rsk}}$ homolog in the budding yeast genome.

Early experiments by Kimelman and colleagues (1987) showed that MPF would periodically become activated and inactivated even in early embryos that were unable to replicate their DNA, suggesting that no DNA replication checkpoint exists in early embryos. Work in other laboratories identified a similar phenomenon in embryos lacking spindle microtubules (Hara et al. 1980; Gerhart et al. 1984). However, Dasso and Newport (1990) showed that the arrest of cell cycle progression in egg extracts by the DNA replication checkpoint could be restored if a "critical nuclear density" was added to the extracts. Subsequent work by Minshull and colleagues (1994), as described above, revealed that the spindle assembly checkpoint induced by nocodazole could also be restored in cycling egg extracts given $>9,000$ sperm nuclei per microliter of extract, and this arrest required the activity of MAPK. Thus, the egg has the potential for monitoring DNA synthesis and spindle assembly, but the proteins mediating such activity either are insufficiently active or are prevented from functioning downstream of activation until a threshold nuclear-to-cytoplasmic ratio has been reached. The threshold level of nuclei or nuclear/ cytoplasmic ratio sufficient for a spindle checkpoint arrest appears to be satisfied in the intact embryo at the gastrulation stage of embryogenesis-20,000 cells (Clute and Masui 1995, 1997).

Given this information, for some years it was thought unlikely that the spindle assembly checkpoint proteins maintain CSF arrest in the egg through inhibition of the $\mathrm{APC} / \mathrm{C}$, because the checkpoint using these proteins is prevented from activating such a mechanism in response to disrupted spindles. However, experiments performed recently in Xenopus egg extracts have demonstrated that inhibition of the APC/C is sufficient to prevent CSF release (Lorca et al. 1998; Vorlaufer and Peters 1998; Peter et al. 2001; Taieb et al. 2001; Reimann and Jackson 2002), and indicated how some of the spindle assembly checkpoint proteins may function during this arrest. First, Lorca and colleagues (1998) cloned the Xenopus homolog of Cdc20/Fizzy, termed xFzy, and showed that $x F z y$ protein is required for exit from CSF arrest. Addition of polyclonal antibodies to xFzy protein to CSF-arrested extracts maintained a metaphase-arrested spindle morphology and prevented sister chromatid separation, even after the addition of a constitutively active form of the calmodulin (CaM)-dependent protein kinase II (CaMKII) enzyme, the target for $\mathrm{Ca}^{2+}$-induced activation of the APC/C (discussed below). In addition, xFzy anti- 
body addition to extracts or immunodepletion of xFzy protein from extracts prevented the degradation of cyclin B1 after calcium addition. Furthermore, Taieb et al. (2001) showed that depletion of xFxy from CSF-arrested oocytes by antisense oligonucleotide injection blocked CSF release after parthenogenetic activation. Other work by Peter and colleagues (2001) found that microinjection of recombinant Mad2 protein arrested oocyte maturation in metaphase of meiosis II, and microinjection of both Mad2 protein and $\alpha-x F z y$ antibody prevented release from CSF arrest after egg activation. In addition, immunoprecipitation of the endogenous APC/C complex from control or $\alpha$-xFzy antibody-treated extracts showed that the APC/C from $\alpha-x F z y$ antibody-treated extracts was unable to polyubiquitinate cyclin B1 in vitro. Lastly, the overexpression of xFzy in CSF extracts caused activation of the APC/C and CSF release in the absence of calcium addition (Reimann and Jackson 2002). This suggests that even in eggs with an intact spindle, the xFxy-mediated activation of the APC/C is important for CSF release on fertilization/activation, and CSF arrest may be maintained in the egg through inhibition of APC/C-mediated degradation by spindle assembly checkpoint proteins such as Mad2.

Although Mos and the MAPK pathway are required to establish CSF arrest during meiosis II, an additional role for Mos protein during Xenopus and mouse oocyte maturation has been identified through the use of antisense oligonucleotides (O'Keefe et al. 1989, 1991; Furuno et al. 1994; Roy et al. 1996). Mos protein is translated from maternal mRNA shortly after PG stimulation of the oocyte. Ablation of Mos in the immature oocytes did not prevent entry or exit from meiosis I; however, the oocytes failed to enter meiosis II. Instead, they exited meiosis I, as witnessed by polar body extrusion, decondensation of their chromatin, formation of a nuclear envelope, and initiation of DNA synthesis. Studies in maturing oocytes deficient in Mos protein or treated with the MEK1-specific inhibitor UO126 showed that the MAPK pathway is necessary for APC/C inhibition after meiosis $\mathrm{I}$ and for the cyclin B resynthesis necessary for entry into meiosis II (Furuno et al. 1994; Gross et al. 2000; Taieb et al. 2001). Mouse or Xenopus oocytes that lack mos enter meiosis I normally, presumably through the activities of the Plx1/Cdc25C pathway (Pahlavan et al. 2000), but fail to enter meiosis II (Roy et al. 1996; Verlhac et al. 1996). Rather, these oocytes enter S phase and synthesize DNA (Furuno et al. 1994). A similar phenomenon occurs in Xenopus oocytes treated with UO126 (Gross et al. 2000). Interestingly, oocytes treated with UO126 degraded microinjected radiolabeled cyclin B1 protein with a half-life of $<10 \mathrm{~min}$, whereas non-UO126-treated oocytes displayed a cyclin $\mathrm{B} 1$ half-life of $>30 \mathrm{~min}$. In addition, hyperphosphorylation of the APC/C subunit Cdc27, detected by large electrophoretic shifts during mitosis or meiosis, correlates with an inactive form of the APC/C in oocytes. In control oocytes, $\mathrm{Cdc} 27$ was hyperphosphorylated, and this correlated with cyclin B1 stability. However, in the UO126-treated oocytes, Cde27 did not become hyperphosphorylated, and cyclin B was rapidly degraded. Although the exact effect of phosphorylation on $\mathrm{Cdc} 27$, and the kinase(s) that mediate it, is unknown, its electrophoretic mobility serves as a useful marker of APC/C activity. Thus, these studies provide further evidence that MAPK activity is directly or indirectly essential for APC/C inhibition and suppression of S phase during oocyte maturation.

The MAPK substrate mediating CSF arrest is the serine/threonine kinase $\mathrm{p} 90^{\mathrm{Rsk}}$, as described previously, and the same may be true for MAPK actions during the meiosis I to II transition. Prevention of exit from M phase caused by UO126 treatment could be achieved through microinjection of mRNA encoding CA-Rsk into these oocytes (Gross et al. 2000, 2001). CA-Rsk mRNA also stabilized the level of endogenous cyclin B protein and restored the hyperphosphorylation of $\mathrm{Cdc} 27$ protein even in the presence of UO126. Thus, $\mathrm{p} 90^{\mathrm{Rsk}}$ is able to mediate the inhibition of the APC/C downstream of the MAPK pathway, suggesting that $\mathrm{p} 90^{\mathrm{Rsk}}$ is the only substrate of MAPK necessary for APC/C inhibition. In addition to mediating APC/C inhibition by MAPK, p90 Rsk also appears to be the target of MAPK responsible for the concurrent increase in cyclin B synthesis in meiosis II in Xenopus (Taieb et al. 2001).

\section{p90 Rsk links the Mos/MAPK pathway to the spindle checkpoint pathway}

MAPK has not been implicated in the spindle assembly checkpoint in yeast mitoses, nor has a p90 Rsk homolog been identified in the budding yeast genome. However, as described earlier, the APC/C is inhibited in a MAPKdependent manner during the spindle assembly checkpoint of mammalian cells, and homologs of many of the genetically identified yeast genes important for the spindle assembly checkpoint have been shown to have a role in checkpoint arrest in higher eukaryotes. One model by which the MAPK/p90 Rsk pathway may mediate $\mathrm{APC} / \mathrm{C}$ inhibition during CSF arrest is through the activation of spindle assembly checkpoint proteins. Of particular interest are the protein kinases Bubl and Mps1, because genetic analysis indicates that these enzymes act upstream of the Mad proteins and have a key role in the checkpoint. This laboratory and others cloned the Xenopus homolog of the yeast serine/threonine protein kinase Bub1 (xBub1; Schwab et al. 2001; Sharp-Baker and Chen 2001). Analysis of endogenous xBub1 protein during oocyte maturation revealed that the protein undergoes phosphorylation coincident with MAPK activation, as witnessed by a decreased electrophoretic mobility in SDS-PAGE, and this phosphorylation correlates with an increase in intrinsic kinase activity. UO126 treatment of oocytes blocked phosphorylation of xBub1, suggesting that the MAPK pathway plays a role upstream of xBub1 activation in vivo. It was found that the phosphorylation of xBub1 in vivo could be rescued through the microinjection of CA-Rsk into UO126treated oocytes (Schwab et al. 2001). This effect appeared to be direct, inasmuch as purified $\mathrm{p} 90^{\text {Rsk }}$ was able to phosphorylate and activate Bubl in vitro (Schwab et al. 
2001). The linkage of $\mathrm{MAPK} / \mathrm{p} 90^{\text {Rsk }}$ to the Bub/Mad pathway is likely to be important for the spindle checkpoint in mammalian cells as well, given the presence of phospho-MAPK and Bub1 on kinetochores during checkpoint activation after spindle disruption. The ability of Mos to globally up-regulate the MAPK pathway during oocyte maturation may serve to activate this checkpoint mechanism for metaphase arrest even in oocytes with an intact spindle, whereas in mitotic cells only the MAPK present on kinetochores and spindle poles is active during the checkpoint (Fig. 3).

These results suggested that the next downstream target of the Mos/MEK1/MAPK/p90 Rsk pathway in establishing CSF arrest may be through the activation of xBub1. This possibility was assessed directly in egg extracts that recapitulate CSF arrest on addition of Mos (Fig. 2B). Immunodepletion of endogenous xBub1 protein from cycling extracts prevented Mos protein from establishing CSF arrest on entry into the next M phase (Tunquist et al. 2002). However, establishment of CSF arrest by Mos could be restored in xBub1-depleted extracts by the readdition of recombinant wild-type, but not kinase dead, xBub1. These results suggest that the kinase activity of $x B u b 1$ is necessary for CSF arrest downstream of the MAPK pathway, and this supports a model by which the $\mathrm{MAPK} / \mathrm{p} 90^{\mathrm{Rsk}}$-dependent activation of $\mathrm{xBubl}$ activates downstream spindle assembly checkpoint proteins, such as Mad1 and Mad2, to inhibit the APC/C and prevent the metaphase/anaphase transition during CSF arrest (Fig. 3).

CSF arrest exhibits APC inhibition independent of the Mos/MEK1/MAPK/p90 ${ }^{\text {Rsk }}$ pathway

The Mos/MEK1/MAPK/p90 Rsk $/ x B u b 1$ proteins are all present and active in meiosis I oocytes, and these proteins have been found to be sufficient for CSF arrest in the egg. The APC/C and its activator Cdc20 are also present during meiosis I (Taieb et al. 2001) and have ubiquitin ligase activity during the meiosis I to II transition, as witnessed by cyclin B degradation. Thus, an important question concerns why metaphase arrest does not occur during meiosis I when all of the known components of CSF activity are present and active. One possibility is that APC/C activation is not needed for segregation of homologous chromosomes in meiosis I, but is needed for sister chromatid segregation and anaphase in meiosis II. Indeed, in Xenopus, complete inhibition of the APC/C in meiosis I has been reported to be insufficient to block progression to meiosis II (Peter et al. 2001; Taieb et al. 2001). In mitosis, APC/C activation is also needed after anaphase for exit from $M$ phase, but $M$ phase of the cell cycle is maintained between meiosis I and II during oocyte maturation, which is consistent with evidence that the APC is not completely activated at anaphase I. A second related question concerns how

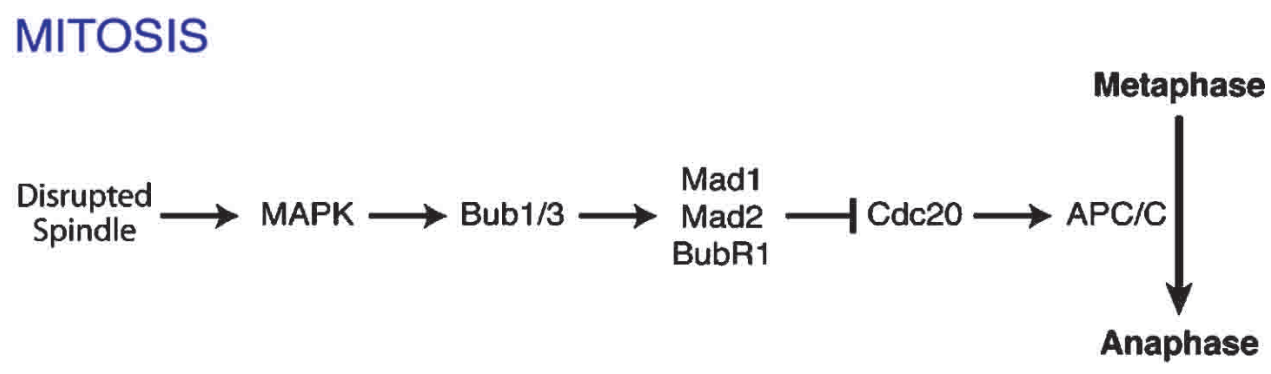

\section{MEIOSIS}

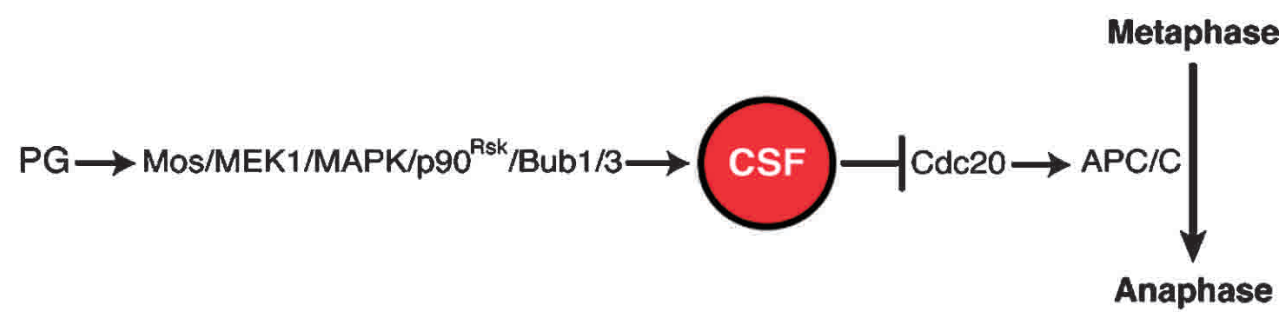

Figure 3. The pathway of metaphase arrest by the spindle checkpoint and by Mos. (Top) During mitosis, unattached kinetochores or unaligned chromosomes from a disrupted spindle lead to activation of MAPK specifically on kinetochores, resulting in activation of the Bub1/3 and Mad1/Mad2/BubR1 pathway. The endpoint of this pathway results in inhibition of the ability of Cdc20 to activate the APC/C for the metaphase/anaphase transition. (Bottom) During meiosis, the expression of the MEKK Mos upon progesterone (PG) treatment leads to global activation of the MAPK pathway throughout the cell culminating in the activation of Bubl even in the presence of an intact spindle. Activated Bub1, possibly acting via the Mad1/Mad2/BubR1 components involved in the spindle checkpoint in somatic cells, causes an inhibition of the ability of Cdc20 to activate the APC/C during CSF arrest. 
the $\mathrm{APC} / \mathrm{C}$ is able to degrade $\sim 50 \%$ of the metaphase level of cyclin B protein during the meiosis I to II transition in the presence of an active MAPK pathway, but maintains the metaphase level of cyclin B during CSF arrest (Fig. 1A). One possibility is that an additional activity, independent of the MAPK pathway, appears on entry into meiosis II and is required for the observed greater $\mathrm{APC} / \mathrm{C}$ inhibition during CSF arrest.

\section{Cyclin E/Cdk2-mediated APC/C inhibition and CSF arrest}

Protein synthesis is required for both meiosis I and II during vertebrate oocyte maturation (Wasserman and Masui 1975). Several proteins, such as Mos and RINGO, are important for entry into meiosis I (Sagata et al. 1989a; Ferby et al. 1999), yet protein synthesis is still needed for meiosis II. One possible candidate for a newly synthesized component important for CSF arrest is the protein kinase Cdk2, which typically functions during the $\mathrm{G}_{1} / \mathrm{S}$ phases of somatic cell cycles. Cdk2 and cyclin E are present at a very low level in resting oocytes and increase markedly prior to meiosis II (Rempel et al. 1995). Ablation of Cdk2 synthesis with antisense oligonucleotides was reported to block CSF arrest (Gabrielli et al. 1993). In addition, CSF arrest could be rescued in oocytes co-injected with antisense oligonucleotides and Cdk2 monomer protein. However, injection of a specific inhibitor of cyclin $\mathrm{E} / \mathrm{Cdk} 2, \mathrm{p} 21^{\mathrm{Cip} 1}$, into oocytes undergoing meiosis had no effect on the ability of these oocytes to arrest in meiosis II, suggesting that Cdk2 activity is not required for CSF arrest (Furuno et al. 1997).

As alluded to previously, CSF arrest is dependent on the inhibition of the APC/C during meiosis II. A recent report by D'Angiolella and colleagues (2001) has shown that cyclin E/Cdk2 activity is also required for stabilization of MPF activity during mitosis in egg extracts. They reported that cyclin E/Cdk2 is inactivated by Tyr 15 phosphorylation after CSF release, and the p2 $1^{\mathrm{Cip} 1}$-mediated loss of cyclin E/Cdk2 activity upon mitotic entry in cycling egg extracts results in premature cyclin B degradation and mitotic exit. In addition, a constitutively active cyclin E/Cdk2 complex (cyclin E/Cdk2 AF) lacking the Thr 14 and Tyr 15 inhibitory phosphorylation sites is able to stabilize the level of cyclin B in cycling egg extracts, suggesting that cyclin $\mathrm{E} / \mathrm{Cdk} 2$ may function during meiosis through inhibition of the APC/C (Tunquist et al. 2002). Evidence suggests this arrest is at metaphase because only cyclin B1, and not cyclin A, is stabilized, and metaphase spindles are present. Additional work from this laboratory has shown that cyclin E/Cdk2 $\mathrm{AF}$ is able to prevent most cyclin $\mathrm{B}$ degradation between meiosis I and II when injected into meiosis I oocytes lacking endogenous cyclin E/Cdk2 activity but containing an active MAPK pathway (Tunquist et al. 2002). These data suggest that both cyclin E/Cdk2 and the MAPK pathway are needed for full APC/C inhibition, and the absence of cyclin $\mathrm{E} / \mathrm{Cdk} 2$ activity before meiosis II prevents maximal APC/C inhibition. In extracts, either the MAPK or cyclin E/Cdk2 pathways is sufficient to cause metaphase arrest. This may explain the results of Furuno et al. (1997), because the Mos/MEK1/MAPK/ p90 Rsk/Bub1 pathway may be sufficient for CSF arrest in intact oocytes, even after inactivation of cyclin $\mathrm{E} / \mathrm{Cdk} 2$ by $\mathrm{p} 21^{\mathrm{Cip} 1}$. Nevertheless, it appears that both the Mos/ MEK1/MAPK/p90 Rsk $/ \mathrm{xBub} 1$ pathway and cyclin E/Cdk2 activity contribute to CSF arrest in the egg.

In yeast and mammalian cells, $G_{1}$ cyclin-dependent kinases, including cyclin $\mathrm{E} / \mathrm{Cdk} 2$, have been implicated in the inactivation of the $\mathrm{APC} / \mathrm{C}$ during interphase in order for mitotic cyclins to reaccumulate (Amon et al. 1994; Knoblich et al. 1994; Zachariae et al. 1998). Therefore, the cyclin E/Cdk2 complex, which functions in the $G_{1}$ phase of somatic cell cycles, may perform a similar function in the CSF-arrested egg to bring about inactivation of the APC/C. Because cyclin E/Cdk2 is the only $\mathrm{G}_{1}$ $\mathrm{Cdk}$ in Xenopus embryos until the midblastula transition (MBT), it is likely the mechanism involved in contributing to CSF arrest is similar to that involved in interphase of early embryonic cycles. However, the target of $\mathrm{G}_{1} \mathrm{Cdks}$ in yeast and mammalian cells, Hct1/Cdh1, is not present in Xenopus until after the MBT (Lorca et al. 1998).

Upon fertilization/activation, the cyclin E/Cdk2 complex becomes phosphorylated on Thr 14 and Tyr 15 residues, causing its inactivation. This suggests that similar to the Mos protein, cyclin E/Cdk2 may be important for CSF arrest in meiosis II, because it also appears during maturation, functions in metaphase arrest, is maintained during this arrest, and is deactivated on fertilization/activation of the egg.

\section{APC/C inhibition by Emi1}

The vertebrate homolog of the Drosophila Rca1 (regulator of cyclin $\underline{A} \underline{1}$ ) gene, termed Emi1 (early mitotic inhibitor $\underline{1}$ ), has recently been identified as a direct binder and inhibitor of Cdc20 in Xenopus egg extracts (Reimann et al. 2001a). Xenopus Emil is present at a constant level during oocyte maturation (Reimann and Jackson 2002). Because Cdc20/Fizzy is the only known APC/C activator in CSF-arrested cells (Lorca et al. 1998), Emil is potentially capable of controlling CSF arrest. Similar to Rcal in Drosophila, in mammalian somatic cell cycles, Emil has been shown to be important in aiding entry into mitosis through the stabilization of the level of cyclin A protein until prometaphase (Hsu et al. 2002). Its level increases in $\mathrm{G}_{1}$ as a result of E2F-dependent transcription and is thought to be important for terminating cyclin A degradation in $G_{1}$. It thus plays a role analogous to that of $\mathrm{G}_{1} \mathrm{Cdks}$ for termination of APC/C activity in late $\mathrm{G}_{1}$ to permit reaccumulation of mitotic cyclins. Consistent with this, overexpression of Emil in $G_{1}$ can cause premature $\mathrm{S}$ phase as a consequence of more rapid accumulation of cyclin A (Hsu et al. 2002).

Cyclin A becomes ubiquitinated and degraded in prometaphase, suggesting a role for cyclin A activity in mitosis mainly in mitotic entry (den Elzen and Pines 2001). Although the level of Emil in mammalian cells is highest in S phase (Hsu et al. 2002), Emil is still present at 
the $\mathrm{G}_{2} / \mathrm{M}$ transition and becomes ubiquitinated and degraded during prometaphase through an APC/C-independent mechanism involving $\beta$-TrCP (P. Jackson, pers. comm.). The $\mathrm{N}$ terminus of Emil contains five Cdk consensus phosphorylation sites, some of which can be phosphorylated by MPF in vitro, and mutation of these five sites to alanine residues, or truncation of the $\mathrm{N}$ terminus, stabilizes the Emil protein level in mitotic extracts (Reimann et al. 2001a). This suggests that the MPF-mediated phosphorylation of Emil in early mitosis might be responsible for the degradation of cyclin $\mathrm{A}$ at prometaphase through destabilization of Emil.

It has been proposed that Emil also prevents the premature degradation of cyclin B upon mitotic entry by binding to $\mathrm{Cdc} 20$ and maintaining APC/C inhibition (Reimann et al. 2001b). Emil is present at a low, but constant, level throughout oocyte maturation and during CSF arrest (Reimann and Jackson 2002). Thus, it was important to determine whether Emil may play a role in the CSF arrest of vertebrate eggs. Overexpression of Emil in CSF extracts prevents the degradation of cyclin B, Mos, and inactivation of the MAPK pathway after the addition of either calcium or a constitutively active form of CaMKII, presumably by binding to Cdc20/Fizzy (Reimann and Jackson 2002). Immunodepletion of the endogenous Emil protein from CSF extracts causes the degradation of cyclin B and CSF release (anaphase) in the absence of calcium addition, apparently due to release of bound Cdc20/xFzy during the immunoprecipitation. This suggests that the amount of Cdc20/xFzy bound to Emil is sufficient for CSF release, even though Cdc20/ $\mathrm{xFzy}$ binding proteins, such as $\mathrm{Mad} 2$, are present in the extract (Chen et al. 1996). In addition, microinjection of recombinant Emil protein into one blastomere of a twocell embryo causes cleavage arrest, although the arrested blastomeres have not yet been studied cytologically (Reimann et al. 2001a). However, the addition of Emil protein to cycling extracts prevents exit from mitosis by stabilizing both cyclin A and B protein levels (Reimann et al. 2001b). This arrest appears distinct from CSF activity because a metaphase arrest in unfertilized eggs caused by Mos protein or in extracts by cyclin E/Cdk2 AF stabilizes only cyclin B protein and results in a meiotic metaphase-arrested spindle. Mad2 protein addition to cycling extracts also prevents exit from mitosis but causes the stabilization of only cyclin B, not cyclin A, protein levels (Reimann et al. 2001b). Consistent with the notion that CSF arrest is related to a spindle checkpoint arrest, it is well established that the spindle assembly checkpoint and CSF arrest in eggs stabilizes only cyclin B, not cyclin A (Whitfield et al. 1990; Bastians et al. 1999; den Elzen and Pines 2001; Geley et al. 2001). XTC cells overexpressing Emil protein arrest in prometaphase, as revealed by DNA and spindle staining (Reimann et al. 2001a). The effect that Emil overexpression has on DNA morphology in arrested blastomeres or in cycling extracts has not yet been reported. Lastly, Emil is synthesized and degraded during each cell cycle in the early embryo, with levels reaching much higher than are present during oocyte maturation, yet CSF arrest is absent after fertilization (Fig. 2B). This suggests that even a high endogenous level of Emil during embryogenesis is unable to cause CSF arrest. Unlike CSF activity, Emil is not degraded within 45 min after fertilization but rather declines during the first mitosis of the zygote (Reimann et al. 2001a). However, similar to cyclin $\mathrm{E} / \mathrm{Cdk} 2$, Emil may represent a $\mathrm{G}_{1} / \mathrm{S}$-phase inhibitor of the APC/C that contributes to CSF arrest because of its expression at a constant level in oocyte maturation (Fig. 4). It might sequester newly synthesized Cdc20/ $\mathrm{xFzy}$ as it accumulates during oocyte maturation (Taieb et al. 2001).

\section{Molecular mechanism of CSF release upon fertilization/activation of the egg}

As described above, a transient increase in cytosolic free $\mathrm{Ca}^{2+}$ occurs universally on fertilization/activation of the vertebrate egg and is critical for the initiation of a multitude of molecular activities important for embryogenesis (for review, see Runft et al. 2002). Egg activation includes all of the molecular events needed to prevent polyspermy, as described previously, as well as various additional changes critical for the transition from a metaphase of meiosis II state to an interphase state of the embryonic cell cycle (i.e., release from CSF arrest). Lohka and Maller (1985) first showed that CSF release,

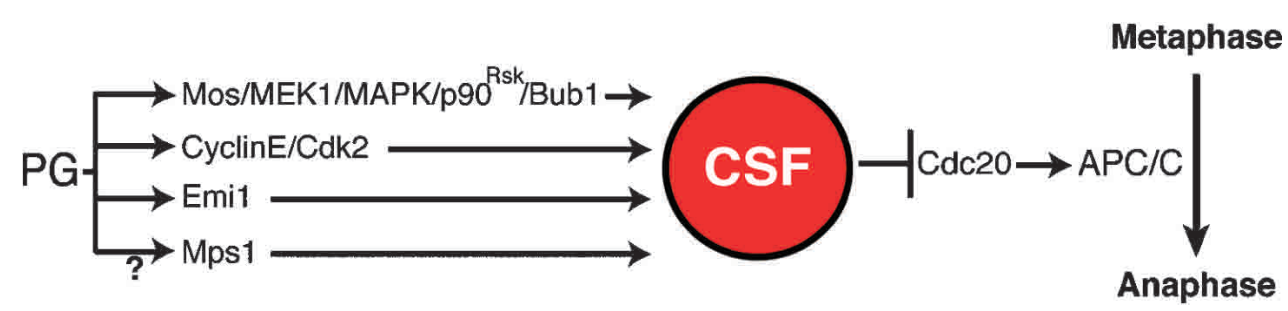

Figure 4. The components of cytostatic factor (CSF) arrest. Progesterone stimulation of immature oocytes causes the synthesis of Mos protein in MI, and cyclin E and Cdk2 protein in MII. Mos activity is required for the activation of the MAPK pathway leading to the Bub1-dependent establishment of CSF arrest. Cyclin E/Cdk2 activity is also sufficient for APC/C inhibition and establishment of CSF arrest independent of the MAPK pathway, at least in extracts. The Cdc20-interacting protein Emil is present in immature oocytes and is necessary for the maintenance of CSF arrest in the egg. CSF arrest is maintained through the inhibition of the APC/C, and the upper three components of CSF arrest depicted in the model have been shown to play a role in the inhibition of the APC/C. The protein kinase Mps1 is also present during CSF arrest and may play a role in its establishment as well. 
assessed by nuclear morphology, could be initiated in CSF extracts by addition of free calcium. It is now known that an important step in this transition involves the degradation of Cohesin, to allow sister chromatid separation, and of meiotic cyclins, in order to exit $M$ phase (Lorca et al. 1998). One key finding was that in eggs cyclin proteolysis by the APC/C is $\mathrm{Ca}^{2+}$ dependent. Lorca and colleagues (1991) transiently increased the concentration of free $\mathrm{Ca}^{2+}$ in egg extracts to the level seen after fertilization by adding $\mathrm{CaCl}_{2}$ followed by EGTA $30 \mathrm{sec}$ later. They found that a $30-\mathrm{sec}$ increase in free $\mathrm{Ca}^{2+}$ is sufficient for the complete degradation of exogenous cyclin B in these extracts, and this degradation required an intact destruction box within the cyclin B protein. This suggested that in order to exit CSF arrest, the APC/C must be activated downstream of the fertilization/activation-induced $\mathrm{Ca}^{2+}$ transient.

An important question concerns the mechanism by which calcium causes CSF release. Many effects of calcium in cells are dependent on binding of calcium to CaM, which then can bind to and activate a variety of intracellular enzymes (for review, see Baluch and Capco 2002; Hoeflich and Ikura 2002; Persechini and Stemmer 2002). A high-affinity pseudosubstrate peptide inhibitor for CaMKII was found to prevent the degradation of cyclin B in the presence of physiological levels of free $\mathrm{Ca}^{2+}$ (Lorca et al. 1991; Matsumoto and Maller 2002). This provided preliminary evidence for a role of CaMKII in mediating the activation of the APC/C downstream of fertilization/activation of the egg. Subsequently, it was found that addition of a constitutively active form of CaMKII to CSF extracts is sufficient to induce the degradation of cyclin $\mathrm{B}$ and inactivation of MPF in the absence of an increase in free $\mathrm{Ca}^{2+}$, and these extracts lost the ability to cause CSF arrest upon injection into one blastomere of a two-cell embryo (Lorca et al. 1993). Furthermore, injection of constitutively active CaMKII protein into CSF-arrested eggs triggered the degradation of cyclin B, inactivation of MPF, and degradation of Mos protein. Lastly, the addition of permeabilized sperm nuclei to CSF extracts causes the assembly of spindles in vitro. In these extracts, it was shown that constitutively active CaMKII protein is sufficient for sister chromatid separation in the absence of $\mathrm{Ca}^{2+}$ addition, and inhibition of CaMKII through the addition of a specific inhibitory peptide could block the $\mathrm{Ca}^{2+}$-triggered separation of sister chromatids (Holloway et al. 1993; Morin et al. 1994). Thus, CaMKII, a molecular target of $\mathrm{Ca}^{2+}-\mathrm{CaM}$, is entirely sufficient to mediate CSF release upon fertilization/activation of the egg. It remains to be seen whether CaMKII functions by directly activating the APC/C, possibly by phosphorylating one or more APC/C subunits, by a distinct and possibly indirect mechanism involving deactivation of Cdc20, or by affecting the binding of Emil and/or Mad2 to Cdc20. It is also possible that CaMKII could cause the activation of a protein phosphatase affecting the activity of the APC/C, because cyclin B proteolysis has previously been shown to be prevented in starfish oocytes treated with the phosphatase inhibitor okadaic acid (OA), and many APC/C subunits are phos- phoproteins (Picard et al. 1989; Abrieu et al. 1996; Lorca et al. 1998). This has been confirmed in Xenopus egg extracts treated with OA (Vorlaufer and Peters 1998). Likewise, the protein tyrosine phosphatase (PTP) inhibitor, ammonium molybdate, was recently shown to prevent the proteolysis of cyclin B and Mos after parthenogenetic activation of mature Xenopus oocytes (Bodart et al. 1999). However, a direct connection has thus far not been elucidated between CaMKII activity and the activation of a protein phosphatase, or a mechanism whereby this may induce the activation of the APC/C.

Lastly, numerous proteins become phosphorylated on tyrosine residues after fertilization/activation of the egg. Ectopic expression of tyrosine kinase receptors has been shown to be sufficient for the parthenogenetic activation of starfish and Xenopus oocytes (Shilling et al. 1994; Yim et al. 1994). A Src family tyrosine kinase becomes activated within minutes after fertilization/activation of sea urchin or Xenopus eggs, and injection of active Src protein into starfish eggs results in parthenogenetic activation (Sato et al. 1996, 2000; Abassi et al. 2000; Giusti et al. 2000). The addition of Src protein to Xenopus CSF extracts induces $\mathrm{Ca}^{2+}$ release, but at a level insufficient for CSF release, possibly due to an inability of these extracts to synthesize sufficient $\mathrm{IP}_{3}$ (Tokmakov et al. 2002). Conversely, addition of recombinant SH2 domain proteins inhibits endogenous Src activity and prevents CSF release upon fertilization/activation (Carroll et al. 1997; Giusti et al. 1999b; Abassi et al. 2000). It has been proposed that one of the functions of Src during CSF release is the direct tyrosine phosphorylation and activation of phospholipase $\mathrm{C} \gamma(\mathrm{PLC} \gamma)$ to increase the production of $\mathrm{IP}_{3}$ in the egg cytosol (Tokmakov et al. 2002). Tyrosine phosphorylation of PLC $\gamma$ is greatly enhanced upon fertilization/activation of the egg or in egg extracts, and a Src family tyrosine kinase was found associated with the SH2 domains of PLC $\gamma$ from starfish eggs after fertilization (Tomes et al. 1996; Giusti et al. 1999a; Tokmakov et al. 2002). An increased level of $\mathrm{IP}_{3}$ in the fertilized egg may accelerate the release of $\mathrm{Ca}^{2+}$ ions from the endoplasmic reticulum and increase the amplitude of the $\mathrm{Ca}^{2+}$-induced activation of the egg (Twigg et al. 1988; Jones and Whittingham 1996; Albrieux et al. 1997; Tokmakov et al. 2001). Tokmakov and colleagues (2002) have shown that $\mathrm{Ca}^{2+}$ release could be prevented in CSF extracts treated with the Src inhibitor PP1, with the PLC inhibitor $\mathrm{U} 73122$, or with the $\mathrm{IP}_{3}$ receptor antagonist heparin. Thus, activation of the Src tyrosine kinase may be one mechanism important for increasing the level of intracellular $\mathrm{Ca}^{2+}$ upon fertilization/activation of the egg.

\section{Establishment versus maintenance of CSF arrest}

Once the activities discussed above have established CSF arrest in the egg, this arrest can be maintained for prolonged periods of time (12-24 h) in both Xenopus and mice (Abbott et al. 1998). An important question concerns whether the activities involved in the establishment of CSF on entry into meiosis II are also required for 
its maintenance until fertilization. Addition of UO126 to CSF-arrested Xenopus egg extracts, for example, causes the inhibition of MEK1 followed by a gradual but eventually complete inactivation of MAPK, yet CSF activity is maintained and the extracts do not undergo parthenogenetic release (Reimann and Jackson 2002; Tunquist et al. 2002). This suggests that the activities of MEK1/MAPK are not required to maintain CSF arrest. However, UO126 treatment of intact mouse eggs has been shown to be sufficient for CSF release and parthenogenetic activation in the absence of calcium addition (Phillips et al. 2002). Thus, the requirement for MAPK during maintenance of CSF arrest in mammals may be more stringent than what is seen in Xenopus eggs. Finally, immunodepletion of downstream components of the MAPK pathway, such as $\mathrm{p} 90^{\mathrm{Rsk}}$ or $\mathrm{xBub1}$, from CSF extracts does not cause the immediate release of these extracts from metaphase arrest, even though both are required to establish the arrest (Bhatt and Ferrell 1999; Sharp-Baker and Chen 2001; Tunquist et al. 2002). The Mos-dependent arrest established during oocyte maturation through the MAPK pathway may be dispensable for maintenance of CSF arrest due to numerous feedback loops in M phase, dependent on MPF activation and other protein kinases. Another possibility is that certain phosphorylated proteins, for example, on kinetochores or some other subcellular location, may be inaccessible to phosphatases during metaphase arrest, and therefore, inactivation of upstream kinases will have no effect on maintaining the phosphorylation state of these proteins.

A similar situation may also occur with cyclin E/Cdk2 activity in mediating the establishment of CSF arrest, but not its maintenance. For example, the addition of p $27^{\mathrm{Xic} 1}$, a potent inhibitor of Cdk2-cyclin E complexes, to CSF extracts causes the complete inhibition of endogenous cyclin E/Cdk2 activity, but is insufficient to release these extracts from metaphase arrest (Tunquist et al. 2002). Further, even addition of both UO126 and p2 $7^{\text {Xic } 1}$ to CSF extracts does not abolish CSF arrest in Xenopus, suggesting that inhibition of both of these known upstream pathways important for the establishment of CSF arrest remains insufficient for CSF release. In contrast, depletion of Emil from CSF extracts does cause CSF release, most likely through the release of bound Cdc20/xFzy during immunodepletion. This result suggests that maintenance of CSF arrest in Xenopus requires Emil-dependent inhibition of Cdc20/xFzy. However, it has not yet been determined whether establishment of CSF arrest by Mos or cyclin $\mathrm{E} / \mathrm{Cdk} 2$ requires Emil.

In some cases components of the spindle checkpoint have been reported to be necessary for maintenance of nocodazole-induced metaphase arrest but not of CSF arrest. Examples include the kinetochore motor CENP-E, Bub1, and Mps1 (Abrieu et al. 2000, 2001; Sharp-Baker and Chen 2001). These reports are difficult to interpret because a nocodazole arrest with large numbers of nuclei is superimposed on a CSF arrest. The spindle checkpoint arrest is defined as failure to exit metaphase arrest (CSF release) on calcium addition. Because CSF arrest and the spindle checkpoint appear to use many of the same proteins (e.g., Bub1, Mps1), perhaps in distinct ways, the spindle checkpoint may be optimally studied in cycling extracts in which CSF activity is absent, as originally described by Minshull et al. (1994).

\section{The mechanism of APC/C inhibition targets Cdc20/xFzy}

A possible model that emerges at this point is that metaphase arrest occurs when multiple upstream pathways converge to bring about a profound inhibition of the $\mathrm{APC} / \mathrm{C}$, as seen after injection of cyclin $\mathrm{E} / \mathrm{Cdk} 2 \mathrm{AF}$ into meiosis I oocytes, which contain an already active MAPK pathway (Fig. 4; Tunquist et al. 2002). In such experiments the Mos/MEK $1 / \mathrm{MAPK} / \mathrm{p} 90^{\text {Rsk }}$ pathway caused inactivation of the APC/C to the extent that only $50 \%$ of cyclin B was degraded at anaphase I, but injection of cyclin E/Cdk2 AF caused a greater inhibition of the APC/C such that no detectable degradation of cyclin B was evident. A similar complete inhibition was seen when Cdc20/xFzy was ablated by antisense oligonucleotides (Taieb et al. 2001). Inhibitory antibodies against Cdc20/xFzy were previously shown to prevent its ability to activate the APC/C after the addition of a constitutively active form of CaMKII to CSF extracts (Lorca et al. 1998; Peter et al. 2001). Thus, a likely mechanism for CSF arrest through APC/C inhibition is via the inactivation of $\mathrm{Cdc} 20 / \mathrm{xFzy}$ through direct binding to inhibitor proteins (i.e., Emil and Mad2), posttranslational modification (i.e., phosphorylation), or both.

Lorca and colleagues (1998) have previously provided evidence that Cdc20/xFzy is a phosphoprotein, dependent on MPF activity, in Xenopus CSF extracts, and the addition of CaMKII to these extracts causes dephosphorylation of Cdc20/xFzy and CSF release. Thus, it has been suggested that phosphorylation of Cde 20 may play a role in mediating its interaction with the APC/C (Lorca et al. 1998; Kotani et al. 1999/. However, subsequent work has suggested that phosphorylation of Cdc20/xFzy is neither sufficient nor required for its interaction with the APC/C, but rather phosphorylation of core APC/C subunits during $M$ phase is required for Cdc20/xFzy binding and subsequent activation of the APC/C /Shteinberg et al. 1999; Kramer et al. 2000). Thus, more work is necessary to determine the importance of Cdc20/xFzy phosphorylation during $\mathrm{M}$ phase and its effect on APC/C activity.

A second mechanism for the inactivation of the APC/C downstream of the MAPK or cyclin E/Cdk2 pathways involves proteins that directly bind to and prevent Cdc20/xFzy from activating the APC/C. This has been shown for both of the Cdc20/xFzy interacting proteins, Emil and Mad2, using oocytes and CSF extracts. Immunodepletion of Emil from CSF extracts was recently shown to be sufficient for CSF release in the absence of calcium addition; it appears that the endogenous Cdc20/ $\mathrm{xFzy}$ bound to Emil was released during the immunoprecipitation procedure (Reimann and Jackson 2002), and Cdc20/xFzy addition to extracts is known to be suffi- 
cient for CSF release (Reimann and Jackson 2002). Recombinant Mad2 protein microinjected into oocytes prevents CSF release after the addition of calcium ionophore or electrical stimulation (Peter et al. 2001), and addition of recombinant Emil protein to CSF extracts prevents CaMKII-mediated CSF release (Reimann and Jackson 2002). These experiments suggest that either protein may be capable of maintaining CSF arrest through inhibition of APC ${ }^{\mathrm{Cdc} 20}$ activity, and that the loss of either of these proteins produces enough unbound Cdc20/xFzy protein for APC/C activation. It would be interesting to determine whether CSF arrest by Mos or cyclin E/Cdk2 could be established in cycling extracts depleted of either Mad2 or Emi1. In summary, it appears as though the upstream Mos/MEK1/MAPK/p90 1 Rsk/ xBub1 and cyclin E/Cdk2 activities important for the establishment of CSF arrest are not required to maintain metaphase arrest once it has been established in meiosis II. Rather, the prolonged maintenance of meiosis II arrest appears dependent on the direct binding of Cdc20/xFzy, by the Emil and Mad2 proteins, to bring about a full inhibition of the $\mathrm{APC} / \mathrm{C}$, and the loss of either of these proteins from the egg is sufficient for APC/C activation and CSF release.

\section{CSF arrest and spindle functions}

A hallmark of CSF arrest is the appearance of the meiotic metaphase spindle. In the maturing oocyte, these spindles are organized in the absence of centrioles, and $\gamma$-tubulin- staining foci are not found at the spindle poles (McKim and Hawley 1995; Waters and Salmon 1995; Heald et al. 1996; Matthies et al. 1996). Rather, chromosomes themselves have been suggested to play a role in organizing microtubules and the meiotic spindle through regulation of microtubule-associated proteins and kinesin-like microtubule motors (Hatsumi and Endow 1992; Theurkauf and Hawley 1992; McKim and Hawley 1995; Waters and Salmon 1995; Matthies et al. 1996; Duesbery et al. 1997; Giunta et al. 2002; Lefebvre et al. 2002). It has been suggested that one of the targets of CSF activity during the establishment of CSF arrest is microtubule-associated proteins important for the establishment of the metaphase spindle (Duesbery et al. 1997; Lefebvre et al. 2002). Protein synthesis is essential for the establishment of the meiotic spindle in meiosis I or II, and treatment of GVBD oocytes with the protein synthesis inhibitor cycloheximide (CHX) causes them to enter interphase instead of proceeding into meiosis II (Wasserman and Masui 1975; Gerhart et al. 1984; Kobayashi et al. 1991; Roy et al. 1991; Huchon et al. 1993; Furuno et al. 1994). However, work by Thibier and colleagues (1997) has found that CHX treatment of oocytes at various time points after meiosis I such that entry into meiosis II is not prevented inhibits the establishment of the meiosis II spindle, but after the spindle has formed $\mathrm{CHX}$ has no effect. This suggests that the cell cycle function of the Mos/MEK1/MAPK/p90 Rsk $/ \mathrm{xBub1}$ and cyclin $\mathrm{E} / \mathrm{Cdk} 2$ pathways in the establishment of CSF arrest in meiosis II is also important for the establishment, but not the maintenance, of the meiotic spindle. However, inasmuch as CSF can arrest the cell cycle in extracts without DNA or spindles, the formation of a metaphase spindle may be a secondary consequence of arresting the cell cycle at metaphase.

\section{Future directions}

The evolution of the pathway of CSF arrest over the past 30 or more years has now led to the expanding field of APC/C inhibition. The Mos protein, originally identified as being sufficient for CSF, has been progressively shown to be a part of a larger pathway important for cyclin B and M-phase stabilization in meiosis I, and the establishment of CSF arrest during meiosis II. Downstream components of this pathway, including the recent identification of the spindle assembly checkpoint kinase Bub1, have been shown to play a role in APC/C inhibition during oocyte maturation or somatic cell mitoses. One mechanism for this function concerns the enlistment of additional spindle checkpoint proteins that are known to operate downstream of Bub1 in mediating APC/C inhibition in somatic cells and that are present in the eggs of vertebrates. Mad1, Mad2, and Mad3 (BubR1) proteins are possible targets of xBub1 activity in CSF-arrested eggs. These proteins inhibit the APC/C by directly binding to Cdc20/xFzy during the spindle checkpoint in somatic cells and in egg extracts supplemented with large numbers of sperm nuclei, and are genetically downstream of Bub1 during the establishment of the spindle checkpoint in yeast. Of particular importance is whether the role for these proteins downstream of the Mos/MEK1/MAPK/ p $90^{\text {Rsk }} / \mathrm{xBub} 1$ pathway for the establishment of CSF arrest is identical to their role in establishing the nocodazole-dependent spindle checkpoint.

Some aspects of metaphase arrest are likely to be distinct even if the same spindle checkpoint components are used. For example, CSF arrest is terminated by calcium, but calcium addition does not overcome the spindle checkpoint (Minshull et al. 1994). Another clear difference is that the spindle checkpoint arrest in metaphase requires kinetochores and microtubule depolymerization, whereas neither is required for CSF arrest. Finally, CSF arrest at metaphase is stable for up to $48 \mathrm{~h}$, whereas cells arrested by nocodazole or other spindle poisons often undergo "adaptation" after a few hours and enter anaphase even with a disrupted spindle. Xenopus egg extracts are likely to prove extremely useful in sorting out the differences between CSF arrest and the nocodazole-dependent spindle checkpoint because CSF arrest occurs under conditions in which the spindle checkpoint is absent, and the spindle checkpoint in extracts is generally induced by adding nuclei and nocodazole after Mos has been degraded and CSF activity is absent (Minshull et al. 1994). Some investigators (Sharp-Baker and Chen 2002; Abrieu et al. 2001) superimpose the spindle checkpoint onto an extract already arrested in metaphase by CSF. The checkpoint is then defined as failure to enter anaphase after calcium addition to terminate CSF arrest. Given the evidence that both forms of met- 
aphase arrest use the Bub/Mad components, defining the mechanism of each type of arrest is best studied under extract conditions in which only CSF or the spindle checkpoint is active. One question important for the spindle checkpoint is what lies upstream of the active MAPK on kinetochores and spindle poles. Mos, which drives the MAPK pathway for CSF arrest in oocytes, is absent in somatic cells. The MAPKK and MAPKKK responsible for MAPK activation in kinetochores is of considerable interest, because it might be part of the mechanism that senses microtubule attachment or tension at the kinetochore. It is worth noting that cyclin A addition to extracts of $\mathrm{G}_{2}$-phase oocytes is capable of activating MAPKK and MAPK, suggesting that CDK activity in mitosis might control MAPK activation (VanRenterghem et al. 1993)

Emil, an additional component important for APC/C inhibition in mammalian cells, has emerged in the past 2 years as a protein capable of inhibiting the APC/C in the egg through its direct binding of the APC/C activator protein Cdc20/xFzy. Emil is present in CSF-arrested eggs, unlike in somatic cell mitosis, in which it is generally degraded in prometaphase. Emil overexpression is sufficient to arrest the cell division of the injected blastomere of a two-cell embryo and is required for CSF maintenance in egg extracts. Thus, it will be important to compare the mechanism of Emil regulation during $M$ phase of somatic cells with that during CSF arrest in vertebrate eggs.

Cyclin E/Cdk2 activity is able to inhibit the degradation of cyclin B protein when added to oocytes undergoing the meiosis I to II transition. Likewise, the addition of a constitutively active form of this complex to cycling egg extracts inhibits cyclin B degradation, leading to metaphase arrest indistinguishable from CSF arrest produced by Mos. However, substrates of cyclin E/Cdk2 in mediating its APC/C inhibition function have yet to be identified. One putative target of cyclin E/Cdk2 activity during meiosis II may be through the phosphorylation of Emil because Emil contains five Cdk consensus phosphorylation sites, and some of these can be phosphorylated by MPF in vitro (Reimann et al. 2001a). An additional target of cyclin E/Cdk2 activity may be the protein kinase Mps1. Mps1 plays a role in metaphase arrest during the spindle assembly checkpoint in yeast and mammalian cells (for review, see Winey and Huneycutt 2002). In mammalian cells, cyclin E/Cdk2 has been reported to phosphorylate Mps1 and promotes its stabilization during centrosome duplication in S phase. Although targets of Mps1 activity, as well as the mechanism of its activation, are still unclear, an attractive potential mechanism for APC/C inhibition downstream of cyclin E/Cdk2 activity is through the activation of Mps1. Abrieu and colleagues (2001) have found that immunodepletion of Mps1 from CSF extracts does not cause the degradation of cyclin $\mathrm{B}$ or premature release from the arrest, although it is required for the spindle checkpoint superimposed on a CSF arrest. Thus, although Mps1 may not be required for maintenance of CSF arrest, it remains to be seen whether its activity is necessary for the establishment of CSF downstream of cyclin E/Cdk2. A third function of cyclin E/Cdk2 activity during CSF arrest may be the inhibition of the protease separase, which is needed in somatic cells for sister chromatid separation by degrading the Cohesin protein important for sister chromatid cohesion. During metaphase in somatic cells, separase is kept inactive by the direct binding of Securin. Securin is an APC/C substrate, and its degradation is important for sister chromatid separation during anaphase. However, it has recently been shown that separase can also be phosphorylated by MPF, and this phosphorylation is sufficient to inhibit its protease activity toward Cohesin even in the absence of bound Securin (Stemmann et al. 2001). Whether phosphorylation of separase by cyclin E/Cdk2 contributes to CSF arrest merits further investigation.

Finally, Cdc20/xFzy becomes phosphorylated during oocyte maturation, and this can be reversed upon CSF release. Thus, an interesting question concerns whether the phosphorylation of Cdc20/xFzy plays a regulatory role in its ability to inhibit the APC/C. The addition of highly active starfish MPF protein to Xenopus interphase extracts containing unphosphorylated Cdc20/xFzy is sufficient to stimulate the phosphorylation of Cdc20/ xFzy (Lorca et al. 1998). This suggests that MPF activity, or a downstream component dependent on its activation, is able to phosphorylate Cdc20/xFzy upon mitotic entry. Identification of the phosphorylation sites in Cdc20 and determination of whether phosphorylation of Cdc20 affects its interaction with Mad1, Mad2, or Emil are important areas for further work.

In addition to ample data suggesting that CSF arrest is ultimately due to APC/C inhibition, additional evidence suggests components of CSF also regulate the activities of microtubule-associated proteins in order to stabilize the metaphase state of the meiotic spindle (Duesbery et al. 1997; Lefebvre et al. 2002). However, this effect is unlikely to be essential for CSF arrest because arrest is maintained in egg extracts lacking DNA and, therefore, kinetochores (Murray and Kirschner 1989; Murray 1991). In mouse oocytes, the MAPK-interacting and spindlestabilizing protein MISS was identified in a yeast 2-hybrid screen for MAPK-binding proteins, and is a substrate of MAPK in vitro (Lefebvre et al. 2002). The prevention of MISS protein synthesis during mouse oocyte maturation is sufficient for destabilization of the meiosis II spindle in eggs. However, CSF arrest of the cell cycle is unaffected biochemically. Likewise, MAPK co-immunoprecipitates and phosphorylates the kinesin-like motor protein CENP-E, as described previously. Abrieu and colleagues (2000) reported that CENP-E is necessary for the nocodazole-induced spindle checkpoint in mitotic egg extracts, but not for maintenance of CSF arrest. Thus, it would be interesting to determine whether CENP-E plays a role in the establishment of CSF arrest and/or the meiotic spindle downstream of the MAPK pathway in meiosis II. In general, it will be important to distinguish whether a metaphase-arrested spindle is a secondary consequence of cell cycle arrest at metaphase versus a specifically modified spindle unique to CSF arrest. Some 
support for the latter possibility comes from evidence that certain epitopes on CENP-E are masked in CSFarrested spindles in Xenopus and mouse eggs, but unmasked in mouse oocytes deficient for the mos gene (Duesbery et al. 1997). The spindle is the site at which anaphase is initiated, and indeed, the targets of CaMKII for CSF release presumably act on the APC/C or other proteins on kinetochores to initiate anaphase in the intact egg. Elucidation of the exact mechanism by which CaMKII releases CSF arrest should be of great interest because it appears dominant over all pathways that contribute to CSF arrest in the unfertilized egg (Fig. 4).

\section{Acknowledgments}

We thank Eleanor Erikson for a critical reading of the manuscript. We are also grateful to Christopher Conn and Andrea Lewellyn for excellent comments during preparation of the manuscript. Work in this laboratory is supported by the National Institutes of Health (GM26743-23 and DK28353-21) and by the Howard Hughes Medical Institute. JLM is an Investigator of the Howard Hughes Medical Institute.

\section{References}

Abassi, Y.A., Carroll, D.J., Giusti, A.F., Belton Jr., R.J., and Foltz, K.R. 2000. Evidence that Src-type tyrosine kinase activity is necessary for initiation of calcium release at fertilization in sea urchin eggs. Dev. Biol. 218: 206-219.

Abbott, A.L., Xu, G., Ducibella, T., and Schultz, R.M. 1998. In vitro culture retards spontaneous activation of cell cycle progression and cortical granule exocytosis that normally occur in in vivo unfertililized mouse eggs. Biol. Reprod. 59: 15151521.

Abrieu, A., Lorca, T., Labbe, J.C., Morin, N., Keyse, S., and Doree, M. 1996. MAP kinase does not inactivate, but rather prevents the cyclin degradation pathway from being turned on in Xenopus egg extracts. J. Cell Sci. 109 (pt 1): 239-246.

Abrieu, A., Doree, M., and Picard, A. 1997. Mitogen-activated protein kinase activation down-regulates a mechanism that inactivates cyclin B-cdc2 kinase in $\mathrm{G}_{2}$-arrested oocytes. Mol. Biol. Cell. 8: 249-261.

Abrieu, A., Brassac, T., Galas, S., Fisher, D., Labbe, J.C., and Doree, M. 1998. The Polo-like kinase Plxl is a component of the MPF amplification loop at the $\mathrm{G}_{2} / \mathrm{M}$-phase transition of the cell cycle in Xenopus eggs. J. Cell Sci. 111 (Pt 12): 17511757.

Abrieu, A., Kahana, J.A., Wood, K.W., and Cleveland, D.W. 2000. CENP-E as an essential component of the mitotic checkpoint in vitro. Cell 102: 817-826.

Abrieu, A., Magnaghi-Jaulin, L., Kahana, J.A., Peter, M., Castro, A., Vigneron, S., Lorca, T., Cleveland, D.W., and Labbe, J.C. 2001. Mps1 is a kinetochore-associated kinase essential for the vertebrate mitotic checkpoint. Cell 106: 83-93.

Ahn, N.G., Seger, R., Bratlien, R.L., Diltz, C.D., Tonks, N.K., and Krebs, E.G. 1991. Multiple components in an epidermal growth factor-stimulated protein kinase cascade: In vitro activation of a myelin basic protein/microtubule-associated protein 2 kinase. J. Biol. Chem. 266: 4220-4227.

Albrieux, M., Sardet, C., and Villaz, M. 1997. The two intracellular $\mathrm{Ca} 2+$ release channels, ryanodine receptor and inositol 1,4,5-trisphosphate receptor, play different roles during fertilization in ascidians. Dev. Biol. 189: 174-185.

Amon, A., Irniger, S., and Nasmyth, K. 1994. Closing the cell cycle circle in yeast: G2 cyclin proteolysis initiated at mitosis persists until the activation of G1 cyclins in the next cycle. Cell 77: 1037-1050.

Baluch, D.P. and Capco, D.G. 2002. Cellular scaffolds in mammalian eggs. Front. Biosci. 7: 1653-1661.

Bastians, H., Topper, L.M., Gorbsky, G.L., and Ruderman, J.V. 1999. Cell cycle-regulated proteolysis of mitotic target proteins. Mol. Biol. Cell 10: 3927-3941.

Basu, J., Logarinho, E., Herrmann, S., Bousbaa, H., Li, Z., Chan, G.K., Yen, T.J., Sunkel, C.E., and Goldberg, M.L. 1998. Localization of the Drosophila checkpoint control protein Bub3 to the kinetochore requires Bub1 but not $\mathrm{Zw10}$ or Rod. Chromosoma 107: 376-385.

Bayaa, M., Booth, R.A., Sheng, Y., and Liu, X.J. 2000. The classical progesterone receptor mediates Xenopus oocyte maturation through a nongenomic mechanism. Proc. Natl. Acad. Sci. 97: 12607-12612.

Belanger, A.M. and Schuetz, A.W. 1975. Precocious induction of activation responses in amphibian oocytes by divalent ionophore A23187. Dev. Biol. 45: 378-381.

Bernat, R.L., Borisy, G.G., Rothfield, N.F., and Earnshaw, W.C. 1990. Injection of anticentromere antibodies in interphase disrupts events required for chromosome movement at mitosis. J. Cell Biol. 111: 1519-1533.

Bhatt, R.R. and Ferrell Jr., J.E. 1999. The protein kinase p90 rsk as an essential mediator of cytostatic factor activity. Science 286: $1362-1365$.

2000. Cloning and characterization of Xenopus Rsk2, the predominant p90 Rsk isozyme in oocytes and eggs. J. Biol. Chem. 275: 32983-32990.

Bodart, J.F., Bechard, D., Bertout, M., Rousseau, A., Gannon, J., Vilain, J.P., and Flament, S. 1999. Inhibition of protein tyrosine phosphatases blocks calcium-induced activation of metaphase II-arrested oocytes of Xenopus laevis. FEBS Lett. 457: 175-178.

Brachet, J. 1950. Chemical embryology. Interscience Publishers, New York,.

Burke, D.J. 2000. Complexity in the spindle checkpoint. Curr. Opin. Genet. Dev. 10: 26-31.

Burton, J.L. and Solomon, M.J. 2001. D box and KEN box motifs in budding yeast Hsllp are required for APC-mediated degradation and direct binding to Cdc20p and Cdh1p. Genes \& Dev. 15: 2381-2395.

Campbell, J.L. and Cohen-Fix, O. 2002. Chromosome cohesion: Ring around the sisters? Trends Biochem. Sci. 27: 492-495.

Carroll, D.J., Ramarao, C.S., Mehlmann, L.M., Roche, S., Terasaki, M., and Jaffe, L.A. 1997. Calcium release at fertilization in starfish eggs is mediated by phospholipase C $\gamma$. J. Cell Biol. 138: 1303-1311.

Castro, A., Peter, M., Magnaghi-Jaulin, L., Vigneron, S., Galas, S., Lorca, T., and Labbe, J.C. 2001. Cyclin B/cdc2 induces c-Mos stability by direct phosphorylation in Xenopus oocytes. Mol. Biol. Cell 12: 2660-2671.

Castro, A., Vigneron, S., Bernis, C., Labbe, J.C., Prigent, C., and Lorca, T. 2002. The D-Box-activating domain (DAD) is a new proteolysis signal that stimulates the silent D-Box sequence of Aurora-A. EMBO Rep. 3: 1209-1214.

Chan, G.K.T., Jablonski, S.A., Sudakin, V., Hittle, J.C., and Yen, T.J. 1999. Human BUBR1 is a mitotic checkpoint kinase that monitors CENP-E functions at kinetochores and binds the cyclosome/APC. J. Cell Biol. 146: 941-954.

Chau, A.S. and Shibuya, E.K. 1998. Mos-induced p42 mitogenactivated protein kinase activation stabilizes $M$-phase in 
Xenopus egg extracts after cyclin destruction. Biol. Cell 90: $565-572$.

Chen, M. and Cooper, J.A. 1997. The $\beta$ subunit of CKII negatively regulates Xenopus oocyte maturation. Proc. Natl. Acad. Sci. 94: 9136-9140.

Chen, M., Li, D., Krebs, E.G., and Cooper, J.A. 1997. The casein kinase II beta subunit binds to Mos and inhibits Mos activity. Mol. Cell Biol. 17: 1904-1912.

Chen, R.H. 2002. BubR1 is essential for kinetochore localization of other spindle checkpoint proteins and its phosphorylation requires Mad1. J. Cell Biol. 158: 487-496.

Chen, R.H., Waters, J.C., Salmon, E.D., and Murray, A.W. 1996. Association of spindle assembly checkpoint component XMAD2 with unattached kinetochores. Science 274: 242246.

Chen, R.H., Shevchenko, A., Mann, M., and Murray, A.W. 1998. Spindle checkpoint protein Xmad1 recruits Xmad2 to unattached kinetochores. J. Cell Biol. 143: 283-295.

Chung, E. and Chen, R.H. 2002. Spindle checkpoint requires Mad1-bound and Mad1-free Mad2. Mol. Biol. Cell 13: 15011511.

Ciosk, R., Zachariae, W., Michaelis, C., Shevchenko, A., Mann, M., and Nasmyth, K. 1998. An ESP1/PDS1 complex regulates loss of sister chromatid cohesion at the metaphase to anaphase transition in yeast. Cell 93: 1067-1076.

Clute, P. and Masui, Y. 1995. Regulation of the appearance of division asynchrony and microtubule-dependent chromosome cycles in Xenopus laevis embryos. Dev. Biol. 171: 273285.

-1997. Microtubule dependence of chromosome cycles in Xenopus laevis blastomeres under the influence of a DNA synthesis inhibitor, aphidicolin. Dev. Biol. 185: 1-13.

Clute, P. and Pines, J. 1999. Temporal and spatial control of cyclin B1 destruction in metaphase. Nat. Cell Biol. 1: 82-87.

Colledge, W.H., Carlton, M.B., Udy, G.B., and Evans, M.J. 1994. Disruption of c-mos causes parthenogenetic development of unfertilized mouse eggs. Nature 370: 65-68.

Crews, C.M. and Erikson, R.L. 1992. Purification of a murine protein-tyrosine/threonine kinase that phosphorylates and activates the Erk-1 gene product: Relationship to the fission yeast byrl gene product. Proc. Natl. Acad. Sci. 89: 82058209.

Crews, C.M., Alessandrini, A., and Erikson, R.L. 1992. The primary structure of MEK, a protein kinase that phosphorylates the ERK gene product. Science 258: 478-480.

Cross, D.A. and Smythe, C. 1998. PD 98059 prevents establishment of the spindle assembly checkpoint and inhibits the $\mathrm{G}_{2}-\mathrm{M}$ transition in meiotic but not mitotic cell cycles in Xenopus. Exp. Cell Res. 241: 12-22.

Cyert, M.S., Scherson, T., and Kirschner, M.W. 1988. Monoclonal antibodies specific for thiophosphorylated proteins recognize Xenopus MPF. Dev. Biol. 129: 209-216.

D'Angiolella, V., Costanzo, V., Gottesman, M.E., Avvedimento, E.V., Gautier, J., and Grieco, D. 2001. Role for cyclin-dependent kinase 2 in mitosis exit. Curr. Biol. 11: 1221-1226.

Dasso, M. and Newport, J.W. 1990. Completion of DNA replication is monitored by a feedback system that controls the initiation of mitosis in vitro: Studies in Xenopus. Cell 61: 811-823.

Dasso, M., Smythe, C., Milarski, K., Kornbluth, S., and Newport, J.W. 1992. DNA replication and progression through the cell cycle. Ciba Found. Symp. 170: 161-180.

den Elzen, N. and Pines, J. 2001. Cyclin A is destroyed in prometaphase and can delay chromosome alignment and anaphase. J. Cell Biol. 153: 121-136.

Doree, M., Peaucellier, G., and Picard, A. 1983. Activity of the maturation-promoting factor and the extent of protein phosphorylation oscillate simultaneously during meiotic maturation of starfish oocytes. Dev. Biol. 99: 489-501.

Draetta, G., Luca, F., Westendorf, J., Brizuela, L., Ruderman, J., and Beach, D. 1989. Cdc2 protein kinase is complexed with both cyclin A and B: Evidence for proteolytic inactivation of MPF. Cell 56: 829-838.

Duckworth, B.C., Weaver, J.S., and Ruderman, J.V. 2002. G2 arrest in Xenopus oocytes depends on phosphorylation of cdc25 by protein kinase A. Proc. Nat1. Acad. Sci. 99: 1679416799.

Duesbery, N.S., Choi, T., Brown, K.D., Wood, K.W., Resau, J., Fukasawa, K., Cleveland, D.W., and Vande Woude, G.F. 1997. CENP-E is an essential kinetochore motor in maturing oocytes and is masked during mos-dependent, cell cycle arrest at metaphase II. Proc. Natl. Acad. Sci. 94: 9165-9170.

Dunphy, W.G. and Kumagai, A. 1991. The cdc25 protein contains an intrinsic phosphatase activity. Cell 67: 189-196.

Dunphy, W.G., Brizuela, L., Beach, D., and Newport, J. 1988. The Xenopus cdc2 protein is a component of MPF, a cytoplasmic regulator of mitosis. Cell 54: 423-431.

Dupre, A., Jessus, C., Ozon, R., and Haccard, O. 2002. Mos is not required for the initiation of meiotic maturation in Xenopus oocytes. EMBO I 21: 4026-4036.

Ellinger-Ziegelbauer, H., Karasuyama, H., Yamada, E., Tsujikawa, K., Todokoro, K., and Nishida, E. 2000. Ste20-like kinase (SLK), a regulatory kinase for polo-like kinase (Plk) during the $\mathrm{G}_{2} / \mathrm{M}$ transition in somatic cells. Genes Cells 5: 491498.

Erikson, E. and Maller, J.L. 1985. A protein kinase from Xenopus eggs specific for ribosomal protein S6. Proc. Natl. Acad. Sci. 82: 742-746.

- 1989. In vivo phosphorylation and activation of ribosomal protein S6 kinases during Xenopus oocyte maturation. J. Biol. Chem. 264: 13711-13717.

Evans, T., Rosenthal, E.T., Youngblom, J., Distel, D., and Hunt, T. 1983. Cyclin: A protein specified by maternal mRNA in sea urchin eggs that is destroyed at each cleavage division. Cell 33: 389-396.

Fagin, J.A. 2002. Branded from the start: Distinct oncogenic initiating events may determine tumor fate in the thyroid. Mol. Endocrinol. 16: 903-911.

Fang, G. 2002. Checkpoint protein BubR1 acts synergistically with Mad2 to inhibit anaphase-promoting complex. Mol. Biol. Cell 13: 755-766.

Ferby, I., Blazquez, M., Palmer, A., Eritja, R., and Nebreda, A.R. 1999. A novel p34cdc2-binding and activating protein that is necessary and sufficient to trigger $\mathrm{G}_{2} / \mathrm{M}$ progression in Xenopus oocytes. Genes \& Dev. 13: 2177-2189.

Ferrell Jr., J.E. 1999. Xenopus oocyte maturation: New lessons from a good egg. BioEssays 21: 833-842.

Ferrell Jr., J.E, Wu, M., Gerhart, J.C., and Martin, G.S. 1991. Cell cycle tyrosine phosphorylation of p34cde2 and a microtubule-associated protein kinase homolog in Xenopus oocytes and eggs. Mol. Cell. Biol. 11: 1965-1971.

Finidori-Lepicard, J., Schorderet-Slatkine, S., Hanoune, J., and Baulieu, E.E. 1981. Progesterone inhibits membrane-bound adenylate cyclase in Xenopus laevis oocytes. Nature 292: 255-257.

Fisher, D.L., Brassac, T., Galas, S., and Doree, M. 1999. Dissociation of MAP kinase activation and MPF activation in hormone-stimulated maturation of Xenopus oocytes. Development 126: 4537-4546.

Freeman, R.S., Meyer, A.N., Li, J., and Donoghue, D.J. 1992. Phosphorylation of conserved serine residues does not regulate the ability of mosxe protein kinase to induce oocyte 
maturation or function as cytostatic factor. J. Cell. Biol. 116: $725-735$.

Frodin, M. and Gammeltoft, S. 1999. Role and regulation of 90 $\mathrm{kDa}$ ribosomal S6 kinase (RSK) in signal transduction. Mol. Cell. Endocrinol. 151: 65-77.

Fulton, B.P. and Whittingham, D.G. 1978. Activation of mammalian oocytes by intracellular injection of calcium. Nature 273: 149-151.

Furuno, N., Nishizawa, M., Okazaki, K., Tanaka, H., Iwashita, J., Nakajo, N., Ogawa, Y., and Sagata, N. 1994. Suppression of DNA replication via Mos function during meiotic divisions in Xenopus oocytes. EMBO J. 13: 2399-2410.

Furuno, N., Ogawa, Y., Iwashita, J., Nakajo, N., and Sagata, N. 1997. Meiotic cell cycle in Xenopus oocytes is independent of cdk2 kinase. EMBO J. 16: 3860-3685.

Gabrielli, B.G., Roy, L.M., and Maller, J.L. 1993. Requirement for Cdk2 in cytostatic factor-mediated metaphase II arrest. Science 259: 1766-1769.

Gardner, R.D. and Burke, D.J. 2000. The spindle checkpoint: Two transitions, two pathways. Trends Cell. Biol. 10: 154158.

Gautier, J. and Maller, J.L. 1991. Cyclin B in Xenopus oocytes: Implications for the mechanism of pre-MPF activation. EMBO J. 10: 177-182.

Gautier, J., Norbury, C., Lohka, M., Nurse, P., and Maller, J. 1988. Purified maturation-promoting factor contains the product of a Xenopus homolog of the fission yeast cell cycle control gene cdc2 $2^{+}$. Cell 54: 433-439.

Gautier, J., Matsukawa, T., Nurse, P., and Maller, J. 1989. Dephosphorylation and activation of Xenopus $\mathrm{p} 34 \mathrm{cdc} 2$ protein kinase during the cell cycle. Nature 339: 626-629.

Gautier, J., Minshull, J., Lohka, M., Glotzer, M., Hunt, T., and Maller, J.L. 1990. Cyclin is a component of maturation-promoting factor from Xenopus. Cell 60: 487-494.

Gautier, J., Solomon, M.J., Booher, R.N., Bazan, J.F., and Kirschner, M.W. 1991. cde25 is a specific tyrosine phosphatase that directly activates p34cdc2. Cell 67: 197-211.

Gebauer, F. and Richter, J.D. 1997. Synthesis and function of Mos: The control switch of vertebrate oocyte meiosis. Bioessays 19: 23-28.

Geley, S., Kramer, G.S., Gieffers, C., Gannon, J., Peters, J.M., and Hunt, T. 2001. Anaphase-promoting complex/cyclosome-dependent proteolysis of human cyclin A starts at the beginning of mitosis and is not subject to the spindle assembly checkpoint. J. Cell Biol. 153: 137-148.

Gerhart, J., Wu, M., and Kirschner, M. 1984. Cell cycle dynamics of an M-phase-specific cytoplasmic factor in Xenopus laevis oocytes and eggs. J. Cell Biol. 98: 1247-1255.

Giunta, K.L., Jang, J.K., Manheim, E.A., Subramanian, G., and McKim, K.S. 2002. subito encodes a kinesin-like protein required for meiotic spindle pole formation in Drosophila melanogaster. Genetics 160: 1489-1501.

Giusti, A.F., Carroll, D.J., Abassi, Y.A., and Foltz, K.R. 1999a. Evidence that a starfish egg Src family tyrosine kinase associates with PLC- $\gamma 1$ SH2 domains at fertilization. Dev. Biol. 208: 189-199.

Giusti, A.F., Carroll, D.J., Abassi, Y.A., Terasaki, M., Foltz, K.R., and Jaffe, L.A. 1999b. Requirement of a Src family kinase for initiating calcium release at fertilization in starfish eggs. J. Biol. Chem. 274: 29318-29322.

Giusti, A.F., Xu, W., Hinkle, B., Terasaki, M., and Jaffe, L.A. 2000. Evidence that fertilization activates starfish eggs by sequential activation of a Src-like kinase and phospholipase cy. J. Biol. Chem. 275: 16788-16794.

Glotzer, M., Murray, A.W., and Kirschner, M.W. 1991. Cyclin is degraded by the ubiquitin pathway. Nature 349: 132-
138.

Goldman, D.S., Kiessling, A.A., Millette, C.F., and Cooper, G.M. 1987. Expression of c-mos RNA in germ cells of male and female mice. Proc. Nat1. Acad. Sci. 84: 4509-4513.

Gorbsky, G.J. and Ricketts, W.A. 1993. Differential expression of a phosphoepitope at the kinetochores of moving chromosomes. J. Cell Biol. 122: 1311-1321.

Gotoh, Y., Moriyama, K., Matsuda, S., Okumura, E., Kishimoto, T., Kawasaki, H., Suzuki, K., Yahara, I., Sakai, H., and Nishida, E. 1991. Xenopus M phase MAP kinase: Isolation of its cDNA and activation by MPF. EMBO J. 10: 2661-2668.

Gotoh, Y., Masuyama, N., Dell, K., Shirakabe, K., and Nishida, E. 1995. Initiation of Xenopus oocyte maturation by activation of the mitogen-activated protein kinase cascade. J. Biol. Chem. 270: 25898-25904.

Gross, S.D., Schwab, M.S., Lewellyn, A.L., and Maller, J.L. 1999. Induction of metaphase arrest in cleaving Xenopus embryos by the protein kinase p90Rsk. Science 286: 1365-1367.

Gross, S.D., Schwab, M.S., Taieb, F.E., Lewellyn, A.L., Qian, Y.W., and Maller, J.L. 2000. The critical role of the MAP kinase pathway in meiosis II in Xenopus oocytes is mediated by p90(Rsk). Curr. Biol. 10: 430-438.

Gross, S.D., Lewellyn, A.L., and Maller, J.L. 2001. A constitutively active form of the protein kinase p90Rsk 1 is sufficient to trigger the $\mathrm{G}_{2} / \mathrm{M}$ transition in Xenopus oocytes. J. Biol. Chem. 276: 46099-46103.

Guerrier, P., Moreau, M., and Doree, M. 1977. Hormonal control of meiosis in starfish: Stimulation of protein phosphorylation induced by 1-methyladenine. Mol. Cell. Endocrinol. 7: 137-150.

Haccard, O., Sarcevic, B., Lewellyn, A., Hartley, R., Roy, L., Izumi, T., Erikson, E., and Maller, J.L. 1993. Induction of metaphase arrest in cleaving Xenopus embryos by MAP kinase. Science 262: 1262-1265.

Haccard, O., Lewellyn, A., Hartley, R.S., Erikson, E., and Maller, J.L. 1995. Induction of Xenopus oocyte meiotic maturation by MAP kinase. Dev. Biol. 168: 677-682.

Hagting, A., Jackman, M., Simpson, K., and Pines, J. 1999. Translocation of cyclin B1 to the nucleus at prophase requires a phosphorylation-dependent nuclear import signal. Curr. Biol. 9: 680-689.

Hara, K., Tydeman, P., and Kirschner, M. 1980. A cytoplasmic clock with the same period as the division cycle in Xenopus eggs. Proc. Natl. Acad. Sci. 77: 462-466.

Harper, J.W., Burton, J.L., and Solomon, M.J. 2002. The anaphase-promoting complex: It's not just for mitosis any more. Genes \& Dev. 16: 2179-2206.

Hartley, R.S., Lewellyn, A.L., and Maller, J.L. 1994. MAP kinase is activated during mesoderm induction in Xenopus laevis. Dev. Biol. 163: 521-524.

Hashimoto, N., Watanabe, N., Furuta, Y., Tamemoto, H., Sagata, N., Yokoyama, M., Okazaki, K., Nagayoshi, M., Takeda, N., Ikawa, Y., et al. 1994. Parthenogenetic activation of oocytes in c-mos-deficient mice. Nature 370: 68-71.

Hatsumi, M. and Endow, S.A. 1992. Mutants of the microtubule motor protein, nonclaret disjunctional, affect spindle structure and chromosome movement in meiosis and mitosis. J. Cell Sci. 101(pt 3): 547-559.

Heald, R., Tournebize, R., Blank, T., Sandaltzopoulos, R., Becker, P., Hyman, A., and Karsenti, E. 1996. Self-organization of microtubules into bipolar spindles around artificial chromosomes in Xenopus egg extracts. Nature 382: 420-425.

Heilbrunn, L.V., Chaet, A.B., Dunn, A., and Wilson, W.L. 1954. Antimitotic substances from ovaries. Biol. Bull. 106: 158168. 
Hendrickson, C., Meyn III, M.A., Morabito, L., and Holloway, S.L. 2001. the KEN box regulates Clb2 proteolysis in $\mathrm{G}_{1}$ and at the metaphase-to-anaphase transition. Curr. Biol. 11: $1781-1787$.

Hoeflich, K.P. and Ikura, M. 2002. Calmodulin in action: Diversity in target recognition and activation mechanisms. Cell 108: 739-742.

Holloway, S.L., Glotzer, M., King, R.W., and Murray, A.W. 1993. Anaphase is initiated by proteolysis rather than by the inactivation of maturation-promoting factor. Cell 73: 13931402.

Hornig, N.C., Knowles, P.P., McDonald, N.Q., and Uhlmann, F. 2002. The dual mechanism of separase regulation by securin. Curr. Biol. 12: 973-982.

Hoyt, M.A., Totis, L., and Roberts, B.T. 1991. S. cerevisiae genes required for cell cycle arrest in response to loss of microtubule function. Cell 66: 507-517.

Hsu, J.Y., Reimann, J.D., Sorensen, C.S., Lukas, J., and Jackson, P.K. 2002. E2F-dependent accumulation of hEmil regulates $S$ phase entry by inhibiting APC(Cdh1). Nat. Cell. Biol. 4: 358-366.

Huang, J. and Raff, J.W. 1999. The disappearance of cyclin B at the end of mitosis is regulated spatially in Drosophila cells. $E M B O$ T. 18: 2184-2195.

Huang, W., Kessler, D.S., and Erikson, R.L. 1995. Biochemical and biological analysis of Mek1 phosphorylation site mutants. Mol. Biol. Cell 6: 237-245.

Huchon, D., Ozon, R., Fischer, E.H., and Demaille, J.G. 1981. The pure inhibitor of cAMP-dependent protein kinase initiates Xenopus laevis meiotic maturation: A 4-step scheme for meiotic maturation. Mol. Cell. Endocrinol. 22: 211-222.

Huchon, D., Rime, H., Jessus, C., and Ozon, R. 1993. Control of metaphase I formation in Xenopus oocyte: Effects of an indestructible cyclin B and of protein synthesis. Biol. Cell. 77: 133-141.

Hwang, L.H., Lau, L.F., Smith, D.L., Mistrot, C.A., Hardwick, K.G., Hwang, E.S., Amon, A., and Murray, A. 1998. Budding yeast Cdc20: A target of the spindle checkpoint. Science 279: 1041-1044.

Ishida, N., Tanaka, K., Tamura, T., Nishizawa, M., Okazaki, K., Sagata, N., and Ichihara, A. 1993. Mos is degraded by the 26S proteasome in a ubiquitin-dependent fashion. FEBS Lett. 324: 345-348.

Jacobs, H.W., Keidel, E., and Lehner, C.F. 2001. A complex degradation signal in cyclin $A$ required for $\mathrm{G}_{1}$ arrest, and a Cterminal region for mitosis. EMBO J. 20: 2376-2386.

Jang, Y.J., Ma, S., Terada, Y., and Erikson, R.L. 2002. Phosphorylation of threonine 210 and the role of serine 137 in the regulation of mammalian polo-like kinase. J. Biol. Chem. 277: 44115-44120.

Jessus, C., Rime, H., Haccard, O., Van Lint, J., Goris, J., Merlevede, W., and Ozon, R. 1991. Tyrosine phosphorylation of p34cdc2 and p42 during meiotic maturation of Xenopus oocyte: Antagonistic action of okadaic acid and 6-DMAP. Development 111: 813-820.

Jones, K.T. and Whittingham, D.G. 1996. A comparison of sperm- and IP3-induced $\mathrm{Ca} 2+$ release in activated and aging mouse oocytes. Dev. Biol. 178: 229-237.

Jones, S.W., Erikson, E., Blenis, J., Maller, J.L., and Erikson, R.L. 1988. A Xenopus ribosomal protein S6 kinase has two apparent kinase domains that are each similar to distinct protein kinases. Proc. Natl. Acad. Sci. 85: 3377-3381.

Kelm, O., Wind, M., Lehmann, W.D., and Nigg, E.A. 2002. Cell cycle-regulated phosphorylation of the Xenopus polo-like kinase Plx1. J. Biol. Chem. 277: 25247-25256.

Keshet, E., Rosenberg, M.P., Mercer, J.A., Propst, F., Vande
Woude, G.F., Jenkins, N.A., and Copeland, N.G. 1988. Developmental regulation of ovarian-specific Mos expression. Oncogene 2: 235-240.

Kimelman, D., Kirschner, M., and Scherson, T. 1987. The events of the midblastula transition in Xenopus are regulated by changes in the cell cycle. Cell 48: 399-407.

King, R.W., Glotzer, M., and Kirschner, M.W. 1996. Mutagenic analysis of the destruction signal of mitotic cyclins and structural characterization of ubiquitinated intermediates. Mol. Biol. Cell 7: 1343-1357.

Knoblich, J.A., Sauer, K., Jones, L., Richardson, H., Saint, R., and Lehner, C. 1994. Cyclin E controls S phase progression and its down-regulation during Drosophila embryogenesis is required for the arrest of cell proliferation. Cell 77: 107-120.

Kobayashi, H., Minshull, J., Ford, C., Golsteyn, R., Poon, R., and Hunt, T. 1991. On the synthesis and destruction of A- and B-type cyclins during oogenesis and meiotic maturation in Xenopus laevis. J. Cell Biol. 114: 755-765.

Kosako, H., Gotoh, Y., Matsuda, S., Ishikawa, M., and Nishida, E. 1992. Xenopus MAP kinase activator is a serine/threonine/tyrosine kinase activated by threonine phosphorylation. EMBO J. 11: 2903-2908.

Kosako, H., Nishida, E., and Gotoh, Y. 1993. cDNA cloning of MAP kinase kinase reveals kinase cascade pathways in yeasts to vertebrates. EMBO J. 12: 787-794.

Kosako, H., Gotoh, Y., and Nishida, E. 1994a. Mitogen-activated protein kinase kinase is required for the mos-induced metaphase arrest. J. Biol. Chem. 269: 28354-28358.

. 1994b. Requirement for the MAP kinase kinase/MAP kinase cascade in Xenopus oocyte maturation. EMBO J. 13: $2131-2138$.

. 1994c. Regulation and function of the MAP kinase cascade in Xenopus oocytes. J. Cell Sci. Suppl. 18: 115-119.

Kotani, S., Tanaka, H., Yasuda, H., and Todokoro, K. 1999. Regulation of APC activity by phosphorylation and regulatory factors. J. Cell Biol. 146: 791-800.

Kramer, E.R., Scheuringer, N., Podtelejnikov, A.V., Mann, M., and Peters, J.M. 2000. Mitotic regulation of the APC activator proteins CDC20 and CDH1. Mol. Biol. Cell 11: 15551569.

Kubiak, J.Z. and Ciemerych, M.A. 2001. Cell cycle regulation in early mouse embryos. Novartis Found. Symp. 237: 79-89; discussion 89-99.

Kubota, H.Y., Yoshimoto, Y., Yoneda, M., and Hiramoto, Y. 1987. Free calcium wave upon activation in Xenopus eggs. Dev. Biol. 119: 129-136.

Kumagai, A. and Dunphy, W.G. 1996. Purification and molecular cloning of Plx1, a Cdc25-regulatory kinase from Xenopus egg extracts. Science 273: 1377-1380.

Labbe, J.C., Capony, J.P., Caput, D., Cavadore, J.C., Derancourt, J., Kaghad, M., Lelias, J.M., Picard, A., and Doree, M. 1989. MPF from starfish oocytes at first meiotic metaphase is a heterodimer containing one molecule of cdc2 and one molecule of cyclin B. EMBO J. 8: 3053-3058.

Ledan, E., Polanski, Z., Terret, M.E., and Maro, B. 2001. Meiotic maturation of the mouse oocyte requires an equilibrium between cyclin B synthesis and degradation. Dev. Biol. 232: 400-413.

Lee, M.S., Ogg, S., Xu, M., Parker, L.L., Donoghue, D.J., Maller, J.L., and Piwnica-Worms, H. 1992. cdc25+ encodes a protein phosphatase that dephosphorylates p34cdc2. Mol. Biol. Cell 3: 73-84.

Lefebvre, C., Terret, M.E., Dijane, A., Rassinier, P., Maro, B., and Verlhac, M.H. 2002. Meiotic spindle stability depends on MAPK-interacting and spindle-stabilizing protein (MISS), a new MAPK substrate. J. Cell Biol. 157: 603-613. 
Levran, D., Farhi, J., Nahum, H., Glezerman, M., and Weissman, A. 2002. Maturation arrest of human oocytes as a cause of infertility. Hum. Reprod. 17: 2781.

Li, R. and Murray, A.W. 1991. Feedback control of mitosis in budding yeast. Cell 66: 519-531.

Li, X. and Nicklas, R.B. 1995. Mitotic forces control a cell-cycle checkpoint. Nature 373: 630-632.

Li, Y., Gorbea, C., Mahaffey, D., Rechsteiner, M., and Benezra, R. 1997. MAD2 associates with the cyclosome/anaphasepromoting complex and inhibits its activity. Proc. Natl. Acad. Sci. USA 94: 12431-12436.

Lillie, F.R. 1912. The fertilizing power of porations of the spermatozoon. J. Exp. Zool. 12: 427-476.

Littlepage, L.E. and Ruderman, J.V. 2002. Identification of a new $\mathrm{APC} / \mathrm{C}$ recognition domain, the $\mathrm{A}$ box, which is required for the Cdh1-dependent destruction of the kinase Aurora-A during mitotic exit. Genes \& Dev. 16: 2274-2285.

Lohka, M.J. and Maller, J.L. 1985. Induction of nuclear envelope breakdown, chromosome condensation, and spindle formation in cell-free extracts. J. Cell Biol. 101: 518-523.

Lohka, M.J., Hayes, M.K., and Maller, J.L. 1988. Purification of maturation-promoting factor, an intracellular regulator of early mitotic events. Proc. Natl. Acad. Sci. 85: 3009-3013.

Lorca, T., Galas, S., Fesquet, D., Devault, A., Cavadore, J.C., and Doree, M. 1991. Degradation of the proto-oncogene product p39mos is not necessary for cyclin proteolysis and exit from meiotic metaphase: Requirement for a $\mathrm{Ca}^{2+}$-calmodulin dependent event. EMBO J. 10: 2087-2093.

Lorca, T., Cruzalegui, F.H., Fesquet, D., Cavadore, J.C., Mery, J., Means, A., and Doree, M. 1993. Calmodulin-dependent protein kinase II mediates inactivation of MPF and CSF upon fertilization of Xenopus eggs. Nature 366: 270-273.

Lorca, T., Castro, A., Martinez, A.M., Vigneron, S., Morin, N., Sigrist, S., Lehner, C., Doree, M., and Labbe, J.C. 1998. Fizzy is required for activation of the APC/cyclosome in Xenopus egg extracts. EMBO J. 17: 3565-3575.

Luca, F.C., Shibuya, E.K., Dohrman, C.E., and Ruderman, J.V. 1991. Both cyclin A delta 60 and B $\delta 97$ are stable and arrest cells in M-phase, but only cyclin B $\delta 97$ turns on cyclin destruction. EMBO J. 10: 4311-4320.

Maller, J.L. and Krebs, E.G. 1977. Progesterone-stimulated meiotic cell division in Xenopus oocytes. Induction by regulatory subunit and inhibition by catalytic subunit of adenosine 3':5'-monophosphate-dependent protein kinase. J. Biol. Chem. 252: 1712-1718.

- 1980. Regulation of oocyte maturation. Curr. Top. Cell Regul. 16: 271-311.

Maller, J., Wu, M., and Gerhart, J.C. 1977. Changes in protein phosphorylation accompanying maturation of Xenopus laevis oocytes. Dev. Biol. 58: 295-312.

Mansour, S.J., Matten, W.T., Hermann, A.S., Candia, J.M., Rong, S., Fukasawa, K., Vande Woude, G.F., and Ahn, N.G. 1994. Transformation of mammalian cells by constitutively active MAP kinase kinase. Science 265: 966-970.

Masui, Y. 2000. The elusive cytostatic factor in the animal egg. Nat. Rev. Mol. Cell Biol. 1: 228-232.

Masui, Y. and Markert, C.L. 1971. Cytoplasmic control of nuclear behavior during meiotic maturation of frog oocytes. J. Exp. Zool. 177: 129-145.

Masui, Y., Meyerhof, P.G., Miller, M.A., and Wasserman, W.J. 1977. Roles of divalent cations in maturation and activation of vertebrate oocytes. Differentiation 9: 49-57.

Matsuda, S., Kosako, H., Takenaka, K., Moriyama, K., Sakai, H., Akiyama, T., Gotoh, Y., and Nishida, E. 1992. Xenopus MAP kinase activator: Identification and function as a key intermediate in the phosphorylation cascade. EMBO J. 11:973-
982.

Matsumoto, Y. and Maller, J.L. 2002. Calcium, calmodulin, and CaMKII requirement for initiation of centrosome duplication in Xenopus egg extracts. Science 295: 499-502.

Matten, W., Daar, I., and Vande Woude, G.F. 1994. Protein kinase $\mathrm{A}$ acts at multiple points to inhibit Xenopus oocyte maturation. Mol. Cell. Biol. 14: 4419-4426.

Matthies, H.J., McDonald, H.B., Goldstein, L.S., and Theurkauf, W.E. 1996. Anastral meiotic spindle morphogenesis: Role of the non-claret disjunctional kinesin-like protein. J. Cell Biol. 134: 455-464.

Maxwell, S.A. and Arlinghaus, R.B. 1985. Serine kinase activity associated with Maloney murine sarcoma virus-124-encoded p37mos. Virology 143: 321-33.

McDonald III, E.R. and El-Deiry, W.S. 2001. Checkpoint genes in cancer. Ann. Med. 33: 113-122.

McKim, K.S. and Hawley, R.S. 1995. Chromosomal control of meiotic cell division. Science 270: 1595-1601.

Mendez, R. and Richter, J.D. 2001. Translational control by CPEB: A means to the end. Nat. Rev. Mol. Cell. Biol. 2: $521-$ 529.

Menkin, V. 1959. Nature of factors regulating the rate of cell division. J. Exp. Zool. 140: 441-470.

Meyerhof, P.G. and Masui, Y. 1977. Ca and Mg control of cytostatic factors from Rana pipiens oocytes which cause metaphase and cleavage arrest. Dev. Biol. 61: 214-229.

Millband, D.N., Campbell, L., and Hardwick, K.G. 2002. The awesome power of multiple model systems: Interpreting the complex nature of spindle checkpoint signaling. Trends Cell. Biol. 12: 205-209.

Minshull, J., Sun, H., Tonks, N.K., and Murray, A.W. 1994. A MAP kinase-dependent spindle assembly checkpoint in Xenopus egg extracts. Cell 79: 475-86.

Monroy, A. 1965. An analysis of the process of activation of protein synthesis upon fertilization. Arch. Biol. 76: 511-522.

Monroy, A., Maggio, R., and Rinaldi, A.M. 1965. Experimentally induced activation of the ribosomes of the unfertilized sea urchin egg. Proc. Natl. Acad. Sci. 54: 107-111.

Morin, N., Abrieu, A., Lorca, T., Martin, F., and Doree, M. 1994. The proteolysis-dependent metaphase to anaphase transition: Calcium/calmodulin-dependent protein kinase II mediates onset of anaphase in extracts prepared from unfertilized Xenopus eggs. EMBO J. 13: 4343-4352.

Moses, R.M. and Masui, Y. 1990. Cytostatic factor (CSF) activity in cytosols extracted from Xenopus laevis eggs. Exp. Cell Res. 186: 66-73.

Mueller, P.R., Coleman, T.R., and Dunphy, W.G. 1995a. Cell cycle regulation of a Xenopus Weel-like kinase. Mol. Biol. Cell 6: 119-134.

Mueller, P.R., Coleman, T.R., Kumagai, A., and Dunphy, W.G. 1995b. Myt1: A membrane-associated inhibitory kinase that phosphorylates Cdc2 on both threonine-14 and tyrosine-15. Science 270: 86-90.

Murray, A.W. 1991. Cell cycle extracts. In Xenopus laevis: practical uses in cell and molecular biology. (eds. B.K. Kay and H.B. Peng), pp. 581-604. Academic Press Inc., San Diego, CA.

Murray, A.W. and Kirschner, M.W. 1989. Cyclin synthesis drives the early embryonic cell cycle. Nature 339: 275-280.

Musacchio, A. and Hardwick, K.G. 2002. The spindle checkpoint: Structural insights into dynamic signalling. Nat. Rev. Mol. Cell. Biol. 3: 731-741.

Mutter, G.L. and Wolgemuth, D.J. 1987. Distinct developmental patterns of c-mos protooncogene expression in female and male mouse germ cells. Proc. Natl. Acad. Sci. 84: 53015305. 
Mutter, G.L., Grills, G.S., and Wolgemuth, D.J. 1988. Evidence for the involvement of the proto-oncogene c-mos in mammalian meiotic maturation and possibly very early embryogenesis. EMBO J. 7: 683-689.

Nakielny, S., Cohen, P., Wu, J., and Sturgill, T. 1992. MAP kinase activator from insulin-stimulated skeletal muscle is a protein threonine/tyrosine kinase. EMBO J. 11: 2123-2129.

Nasmyth, K., Peters, J.M., and Uhlmann, F. 2000. Splitting the chromosome: Cutting the ties that bind sister chromatids. Science 288: 1379-1385.

Nebreda, A.R. and Hunt, T. 1993. The c-mos proto-oncogene protein kinase turns on and maintains the activity of MAP kinase, but not MPF, in cell-free extracts of Xenopus oocytes and eggs. EMBO J. 12: 1979-1986.

Nishizawa, M., Okazaki, K., Furuno, N., Watanabe, N., and Sagata, N. 1992. The "second-codon rule" and autophosphorylation govern the stability and activity of Mos during the meiotic cell cycle in Xenopus oocytes. EMBO J. 11: 24332446.

Nishizawa, M., Furuno, N., Okazaki, K., Tanaka, H., Ogawa, Y., and Sagata, N. 1993. Degradation of Mos by the N-terminal proline (Pro2)-dependent ubiquitin pathway on fertilization of Xenopus eggs: Possible significance of natural selection for Pro2 in Mos. EMBO J. 12: 4021-4027.

Nuccitelli, R., Webb, D.J., Lagier, S.T., and Matson, G.B. 1981. 31P NMR reveals increased intracellular $\mathrm{pH}$ after fertilization in Xenopus eggs. Proc. Natl. Acad. Sci. 78: 4421-4425.

Nurse, P. 1990. Universal control mechanism regulating onset of M-phase. Nature 344: 503-508.

O'Keefe, S.J., Wolfes, H., Kiessling, A.A., and Cooper, G.M. 1989. Microinjection of antisense c-mos oligonucleotides prevents meiosis II in the maturing mouse egg. Proc. Natl. Acad. Sci. 86: 7038-7042.

O'Keefe, S.J., Kiessling, A.A., and Cooper, G.M. 1991. The cmos gene product is required for cyclin $\mathrm{B}$ accumulation during meiosis of mouse eggs. Proc. Nat1. Acad. Sci. 88: 78697872.

Osanai, K. 1967. Inhibition of development with the extract from the unfertilized eggs of the Japanese Palolo. Sci. Rep. Tohuku Univ., Ser. 4 323: 129-134.

Pahlavan, G., Polanski, Z., Kalab, P., Golsteyn, R., Nigg, E.A., and Maro, B. 2000. Characterization of polo-like kinase 1 during meiotic maturation of the mouse oocyte. Dev. Biol. 220: 392-400.

Palmer, A. and Nebreda, A.R. 2000. The activation of MAP kinase and $\mathrm{p} 34 \mathrm{cdc} 2 / \mathrm{cyclin} \mathrm{B}$ during the meiotic maturation of Xenopus oocytes. Prog. Cell Cycle Res. 4: 131-143.

Palmer, A., Gavin, A.C., and Nebreda, A.R. 1998. A link between MAP kinase and p34(cdc2)/cyclin B during oocyte maturation: p90(rsk) phosphorylates and inactivates the p34(cdc2) inhibitory kinase Myt1. EMBO J. 17: 5037-5047.

Papkoff, J., Verma, I.M., and Hunter, T. 1982. Detection of a transforming gene product in cells transformed by Moloney murine sarcoma virus. Cell 29: 417-426.

Paules, R.S., Buccione, R., Moschel, R.C., Vande Woude, G.F., and Eppig, J.J. 1989. Mouse Mos protooncogene product is present and functions during oogenesis. Proc. Natl. Acad. Sci. 86: 5395-5399.

Persechini, A. and Stemmer, P.M. 2002. Calmodulin is a limiting factor in the cell. Trends Cardiovasc. Med. 12: 32-37.

Peter, M., Castro, A., Lorca, T., Le Peuch, C., Magnaghi-Jaulin, L., Doree, M., and Labbe, J.C. 2001. The APC is dispensable for first meiotic anaphase in Xenopus oocytes. Nat. Cell. Biol. 3: 83-87.

Peter, M., Labbe, J.C., Doree, M., and Mandart, E. 2002. A new role for Mos in Xenopus oocyte maturation: Targeting Myt1 independently of MAPK. Development 129: 2129-2139.

Petersen, B.O., Wagener, C., Marinoni, F., Kramer, E.R., Melixetian, M., Denchi, E.L., Gieffers, C., Matteucci, C., Peters, J.M., and Helin, K. 2000. Cell cycle- and cell growth-regulated proteolysis of mammalian CDC6 is dependent on APCCdh1. Genes Dev. 14: 2330-2343.

Pfleger, C.M. and Kirschner, M.W. 2000. The KEN box: An APC recognition signal distinct from the D box targeted by Cdh1. Genes Dev. 14: 655-665.

Phillips, K.P., Petrunewich, M.A., Collins, J.L., Booth, R.A., Liu, X.J., and Baltz, J.M. 2002. Inhibition of MEK or cde2 kinase parthenogenetically activates mouse eggs and yields the same phenotypes as $\mathrm{Mos}^{-/-}$parthenogenotes. Dev. Biol. 247: 210-223.

Picard, A., Capony, J.P., Brautigan, D.L., and Doree, M. 1989. Involvement of protein phosphatases 1 and $2 \mathrm{~A}$ in the control of $\mathrm{M}$ phase-promoting factor activity in starfish. J. Cell Biol. 109: 3347-3354.

Pijnacker, L.P. and Ferwerda, M.A. 1976. Experiments on blocking and unblocking of first meiotic metaphase in eggs of the parthenogenetic stick insect Carausius morosus $\mathrm{Br}$. (Phasmida, Insecta). J. Embryol. Exp. Morphol. 36: 383-394.

Pines, J. and Hunter, T. 1994. The differential localization of human cyclins $\mathrm{A}$ and $\mathrm{B}$ is due to a cytoplasmic retention signal in cyclin B. EMBO J. 13: 3772-3781.

Posada, J. and Cooper, J.A. 1992. Requirements for phosphorylation of MAP kinase during meiosis in Xenopus oocytes. Science 255: 212-215.

Posada, J., Sanghera, J., Pelech, S., Aebersold, R., and Cooper, J.A. 1991. Tyrosine phosphorylation and activation of homologous protein kinases during oocyte maturation and mitogenic activation of fibroblasts. Mol. Cell. Biol. 11: 25172528.

Posada, J., Yew, N., Ahn, N.G., Vande Woude, G.F., and Cooper, J.A. 1993. Mos stimulates MAP kinase in Xenopus oocytes and activates a MAP kinase kinase in vitro. Mol. Cell. Biol. 13: $2546-2553$.

Propst, F. and Vande Woude, G.F. 1985. Expression of c-mos proto-oncogene transcripts in mouse tissues. Nature 315: 516-518.

Propst, F., Rosenberg, M.P., Iyer, A., Kaul, K., and Vande Woude, G.F. 1987. c-mos proto-oncogene RNA transcripts in mouse tissues: Structural features, developmental regulation, and localization in specific cell types. Mol. Cell. Biol. 7: 16291637.

Qian, Y.W., Erikson, E., and Maller, J.L. 1998. Purification and cloning of a protein kinase that phosphorylates and activates the polo-like kinase Plx1. Science 282: 1701-1704.

1999. Mitotic effects of a constitutively active mutant of the Xenopus polo-like kinase Plx1. Mol. Cell. Biol. 19: 86258632.

Qian, Y.W., Erikson, E., Taieb, F.E., and Maller, J.L. 2001. The polo-like kinase $\mathrm{Plx} 1$ is required for activation of the phosphatase Cdc25C and cyclin B-Cdc2 in Xenopus oocytes. Mol. Biol. Cell 12: 1791-1799.

Reimann, J.D. and Jackson, P.K. 2002. Emil is required for cytostatic factor arrest in vertebrate eggs. Nature 416: 850854.

Reimann, J.D., Freed, E., Hsu, J.Y., Kramer, E.R., Peters, J.M., and Jackson, P.K. 2001a. Emil is a mitotic regulator that interacts with Cdc20 and inhibits the anaphase promoting complex. Cell 105: 645-655.

Reimann, J.D., Gardner, B.E., Margottin-Goguet, F., and Jackson, P.K. 2001b. Emil regulates the anaphase-promoting complex by a different mechanism than Mad2 proteins. Genes Dev. 15: 3278-3285. 
Rempel, R.E., Sleight, S.B., and Maller, J.L. 1995. Maternal Xenopus Cdk2-cyclin E complexes function during meiotic and early embryonic cell cycles that lack a $\mathrm{G}_{1}$ phase. J. Biol. Chem. 270: 6843-6855.

Rieder, C.L., Cole, R.W., Khodjakov, A., and Sluder, G. 1995. The checkpoint delaying anaphase in response to chromosome monoorientation is mediated by an inhibitory signal produced by unattached kinetochores. J. Cell Biol. 130: 941948.

Rime, H., Haccard, O., and Ozon, R. 1992. Activation of p34cdc2 kinase by cyclin is negatively regulated by cyclic amp-dependent protein kinase in Xenopus oocytes. Dev. Biol. 151: 105-110.

Roshak, A.K., Capper, E.A., Imburgia, C., Fornwald, J., Scott, G., and Marshall, L.A. 2000. The human polo-like kinase, PLK, regulates cdc2/cyclin B through phosphorylation and activation of the cdc25C phosphatase. Cell Signal. 12: 405-411.

Roy, L.M., Swenson, K.I., Walker, D.H., Gabrielli, B.G., Li, R.S., Piwnica-Worms, H., and Maller, J.L. 1991. Activation of p34cdc2 kinase by cyclin A. J. Cell Biol. 113: 507-514.

Roy, L.M., Haccard, O., Izumi, T., Lattes, B.G., Lewellyn, A.L., and Maller, J.L. 1996. Mos proto-oncogene function during oocyte maturation in Xenopus. Oncogene 12: 2203-2211.

Runft, L.L., Jaffe, L.A., and Mehlmann, L.M. 2002. Egg activation at fertilization: Where it all begins. Dev. Biol. 245: 237254.

Sadler, S.E. and Maller, J.L. 1981. Progesterone inhibits adenylate cyclase in Xenopus oocytes: Action on the guanine nucleotide regulatory protein. I. Biol. Chem. 256: 63686373.

Sagata, N., Oskarsson, M., Copeland, T., Brumbaugh, J., and Vande Woude, G.F. 1988. Function of c-mos proto-oncogene product in meiotic maturation in Xenopus oocytes. Nature 335: 519-525.

Sagata, N., Daar, I., Oskarsson, M., Showalter, S.D., and Vande Woude, G.F. 1989a. The product of the mos proto-oncogene as a candidate "initiator" for oocyte maturation. Science 245: 643-646.

Sagata, N., Watanabe, N., Vande Woude, G.F., and Ikawa, Y. $1989 \mathrm{~b}$. The c-mos proto-oncogene product is a cytostatic factor responsible for meiotic arrest in vertebrate eggs. Nature 342: 512-518.

Sarcevic, B., Erikson, E., and Maller, J.L. 1993. Purification and characterization of a mitogen-activated protein kinase tyrosine phosphatase from Xenopus eggs. J. Biol. Chem. 268: 25075-25083.

Sato, K., Aoto, M., Mori, K., Akasofu, S., Tokmakov, A.A., Sahara, S., and Fukami, Y. 1996. Purification and characterization of a Src-related p57 protein-tyrosine kinase from Xenopus oocytes: Isolation of an inactive form of the enzyme and its activation and translocation upon fertilization. J. Biol. Chem. 271: 13250-13257.

Sato, K., Tokmakov, A.A., Iwasaki, T., and Fukami, Y. 2000. Tyrosine kinase-dependent activation of phospholipase $\mathrm{C} \gamma$ is required for calcium transient in Xenopus egg fertilization. Dev. Biol. 224: 453-469.

Schmidt, M., Oskarsson, M.K., Dunn, J.K., Blair, D.G., Hughes, S., Propst, F., and Vande Woude, G.F. 1988. Chicken homo$\log$ of the mos proto-oncogene. Mol. Cell. Biol. 8: 923-929.

Schmitt, A. and Nebreda, A.R. 2002. Signalling pathways in oocyte meiotic maturation. J. Cell Sci. 115: 2457-2459.

Schroeder, T.E. and Strickland, D.L. 1974. Ionophore A23187, calcium and contractility in frog eggs. Exp. Cell Res. 83: $139-142$.

Schuetz, A.W. 1975. Cytoplasmic activation of starfish oocytes by sperm and divalent ionophore A-23187. I. Cell Biol.
66: 86-94.

Schwab, M.S., Roberts, B.T., Gross, S.D., Tunquist, B.J., Taieb, F.E., Lewellyn, A.L., and Maller, J.L. 2001. Bub1 is activated by the protein kinase p90(Rsk) during Xenopus oocyte maturation. Curr. Biol. 11: 141-150.

Shah, J.V. and Cleveland, D.W. 2000. Waiting for anaphase: Mad2 and the spindle assembly checkpoint. Cell 103: 9971000.

Shapiro, P.S., Vaisberg, E., Hunt, A.J., Tolwinski, N.S., Whalen, A.M., McIntosh, J.R., and Ahn, N.G. 1998. Activation of the MKK/ERK pathway during somatic cell mitosis: Direct interactions of active ERK with kinetochores and regulation of the mitotic 3F3/2 phosphoantigen. I. Cell Biol. 142: 15331545.

Sharp-Baker, H. and Chen, R.H. 2001. Spindle checkpoint protein Bub1 is required for kinetochore localization of Mad1, Mad2, Bub3, and CENP-E, independently of its kinase activity. J. Cell Biol. 153: 1239-1250.

Sheets, M.D., Fox, C.A., Hunt, T., Vande Woude, G., and Wickens, M. 1994. The 3'-untranslated regions of c-mos and cyclin mRNAs stimulate translation by regulating cytoplasmic polyadenylation. Genes Dev. 8: 926-938.

Sheets, M.D., Wu, M., and Wickens, M. 1995. Polyadenylation of c-mos mRNA as a control point in Xenopus meiotic maturation. Nature 374: 511-516.

Sheng, J., Kumagai, A., Dunphy, W.G., and Varshavsky, A. 2002. Dissection of c-MOS degron. EMBO J. 21: 6061-6071.

Shibuya, E.K. and Masui, Y. 1988. Stabilization and enhancement of primary cytostatic factor (CSF) by ATP and NaF in amphibian egg cytosols. Dev. Biol. 129: 253-64.

- 1989. Molecular characteristics of cytostatic factors in amphibian egg cytosols. Development 106: 799-808.

Shibuya, E.K. and Ruderman, J.V. 1993. Mos induces the in vitro activation of mitogen-activated protein kinases in lysates of frog oocytes and mammalian somatic cells. Mol. Biol. Cell 4: 781-790.

Shilling, F.M., Carroll, D.J., Muslin, A.J., Escobedo, J.A., Williams, L.T., and Jaffe, L.A. 1994. Evidence for both tyrosine kinase and G-protein-coupled pathways leading to starfish egg activation. Dev. Biol. 162: 590-599.

Shteinberg, M., Protopopov, Y., Listovsky, T., Brandeis, M., and Hershko, A. 1999. Phosphorylation of the cyclosome is required for its stimulation by Fizzy/cdc20. Biochem. Biophys. Res. Commun. 260: 193-198.

Speaker, M.G. and Butcher, F.R. 1977. Cyclic nucleotide fluctuations during steroid induced meiotic maturation of frog oocytes. Nature 267: 848-850.

Steinhardt, R.A., Epel, D., Carroll Jr., E.J., and Yanagimachi, R. 1974. Is calcium ionophore a universal activator for unfertilised eggs? Nature 252: 41-43.

Stemmann, O., Zou, H., Gerber, S.A., Gygi, S.P., and Kirschner, M.W. 2001. Dual inhibition of sister chromatid separation at metaphase. Cell 107: 715-726.

Stith, B.J. and Maller, J.L. 1984. The effect of insulin on intracellular ph and ribosomal protein S6 phosphorylation in oocytes of Xenopus laevis. Dev. Biol. 102: 79-89.

- 1985. Increased intracellular $\mathrm{pH}$ is not necessary for ribosomal protein S6 phosphorylation, increased protein synthesis, or germinal vesicle breakdown in Xenopus oocytes. Dev. Biol. 107: 460-469.

Strausfeld, U., Labbe, J.C., Fesquet, D., Cavadore, J.C., Picard, A., Sadhu, K., Russell, P., and Doree, M. 1991. Dephosphorylation and activation of a p34cdc2/cyclin B complex in vitro by human CDC25 protein. Nature 351: 242-245.

Stucke, V.M., Sillje, H.H., Arnaud, L., and Nigg, E.A. 2002. Human Mps1 kinase is required for the spindle assembly check- 
point but not for centrosome duplication. EMBO J. 21: 17231732.

Sturgill, T.W., Ray, L.B., Erikson, E., and Maller, J.L. 1988. Insulin-stimulated MAP-2 kinase phosphorylates and activates ribosomal protein S6 kinase II. Nature 334: 715-718.

Taieb, F.E., Gross, S.D., Lewellyn, A.L., and Maller, J.L. 2001. Activation of the anaphase-promoting complex and degradation of cyclin B is not required for progression from Meiosis I to II in Xenopus oocytes. Curr. Biol. 11: 508-513.

Takenaka, K., Gotoh, Y., and Nishida, E. 1997. MAP kinase is required for the spindle assembly checkpoint but is dispensable for the normal $M$ phase entry and exit in Xenopus egg cell cycle extracts. J. Cell Biol. 136: 1091-1097.

Taylor, S.S. 1999. Chromosome segregation: Dual control ensures fidelity. Curr. Biol. 9: R562-R564.

Taylor, S.S., Ha, E., and McKeon, F. 1998. The human homologue of Bub3 is required for kinetochore localization of Bub1 and a Mad3/Bub1-related protein kinase. J. Cell Biol. 142: $1-11$.

Theurkauf, W.E. and Hawley, R.S. 1992. Meiotic spindle assembly in Drosophila females: Behavior of nonexchange chromosomes and the effects of mutations in the nod kinesinlike protein. J. Cell Biol. 116: 1167-1180.

Thibier, C., De Smedt, V., Poulhe, R., Huchon, D., Jessus, C., and Ozon, R. 1997. In vivo regulation of cytostatic activity in Xenopus metaphase II-arrested oocytes. Dev. Biol. 185: 5566.

Tian, J., Kim, S., Heilig, E., and Ruderman, J.V. 2000. Identification of XPR-1, a progesterone receptor required for Xenopus oocyte activation. Proc. Natl. Acad. Sci. 97: 1435814363.

Tobe, K., Kadowaki, T., Hara, K., Gotoh, Y., Kosako, H., Matsuda, S., Tamemoto, H., Ueki, K., Akanuma, Y., Nishida, E., et al. 1992. Sequential activation of MAP kinase activator, MAP kinases, and S6 peptide kinase in intact rat liver following insulin injection. J. Biol. Chem. 267:2108921097.

Tokmakov, A.A., Sato, K.I., and Fukami, Y. 2001. Calcium oscillations in Xenopus egg cycling extracts. J. Cell. Biochem. 82: 89-97.

Tokmakov, A.A., Sato, K.I., Iwasaki, T., and Fukami, Y. 2002. Src kinase induces calcium release in Xenopus egg extracts via PLCgamma and IP(3)-dependent mechanism. Cell Calcium 32: 11-20.

Tomes, C.N., McMaster, C.R., and Saling, P.M. 1996. Activation of mouse sperm phosphatidylinositol-4,5 bisphosphatephospholipase $\mathrm{C}$ by zona pellucida is modulated by tyrosine phosphorylation. Mol. Reprod. Dev. 43: 196-204.

Tomkiel, J., Cooke, C.A., Saitoh, H., Bernat, R.L., and Earnshaw, W.C. 1994. CENP-C is required for maintaining proper kinetochore size and for a timely transition to anaphase. J. Cell Biol. 125: 531-545.

Toyoshima-Morimoto, F., Taniguchi, E., Shinya, N., Iwamatsu, A., and Nishida, E. 2001. Polo-like kinase 1 phosphorylates cyclin $\mathrm{B} 1$ and targets it to the nucleus during prophase. $\mathrm{Na}$ ture 410: 215-220.

Toyoshima-Morimoto, F., Taniguchi, E., and Nishida, E. 2002. Plk1 promotes nuclear translocation of human Cdc25C during prophase. EMBO Rep. 3: 341-348.

Tugendreich, S., Tomkiel, J., Earnshaw, W., and Hieter, P. 1995. $\mathrm{CDC} 27 \mathrm{Hs}$ colocalizes with $\mathrm{CDC} 16 \mathrm{Hs}$ to the centrosome and mitotic spindle and is essential for the metaphase to anaphase transition. Cell 81: 261-268.

Tunquist, B.J., Schwab, M.S., Chen, L.G., and Maller, J.L. 2002. The spindle checkpoint kinase Bub1 and cyclin E/Cdk2 both contribute to the establishment of meiotic metaphase arrest by cytostatic factor. Curr. Biol. 12: 1027-1033.

Twigg, J., Patel, R., and Whitaker, M. 1988. Translational control of InsP3-induced chromatin condensation during the early cell cycles of sea urchin embryos. Nature 332: $366-$ 369.

Ueno, S. and Sagata, N. 2002. Requirement for both EDEN and AUUUA motifs in translational arrest of Mos mRNA upon fertilization of Xenopus eggs. Dev. Biol. 250: 156-167.

Uhlmann, F. 2001. Secured cutting: Controlling separase at the metaphase to anaphase transition. EMBO Rep. 2: 487-492.

Uhlmann, F., Lottspeich, F., and Nasmyth, K. 1999. Sister-chromatid separation at anaphase onset is promoted by cleavage of the cohesin subunit Scc1. Nature 400: 37-42.

VanRenterghem, B., Gibbs, J.B., and Maller, J.L. 1993. Reconstitution of p21ras-dependent and -independent mitogen-activated protein kinase activation in a cell-free system. J. Biol. Chem. 268: 19935-19938.

Verlhac, M.H., Kubiak, J.Z., Weber, M., Geraud, G., Colledge, W.H., Evans, M.J., and Maro, B. 1996. Mos is required for MAP kinase activation and is involved in microtubule organization during meiotic maturation in the mouse. Development 122: 815-822.

Verlhac, M.H., Lefebvre, C., Kubiak, J.Z., Umbhauer, M., Rassinier, P., Colledge, W., and Maro, B. 2000. Mos activates MAP kinase in mouse oocytes through two opposite pathways. EMBO J. 19: 6065-6074.

Vorlaufer, E. and Peters, J.M. 1998. Regulation of the cyclin B degradation system by an inhibitor of mitotic proteolysis. Mol. Biol. Cell 9: 1817-1831.

Wang, X.M., Zhai, Y., and Ferrell Jr., J.E. 1997. A role for mitogen-activated protein kinase in the spindle assembly checkpoint in XTC cells. J. Cell Biol. 137: 433-443.

Wasserman, W.J. and Masui, Y. 1975. Effects of cyclohexamide on a cytoplasmic factor initiating meiotic maturation in Xenopus oocytes. Exp. Cell Res. 91: 381-388.

Wassmann, K. and Benezra, R. 2001. Mitotic checkpoints: From yeast to cancer. Curr. Opin. Genet. Dev. 11: 83-90.

Watanabe, N., Vande Woude, G.F., Ikawa, Y., and Sagata, N. 1989. Specific proteolysis of the c-mos proto-oncogene product by calpain on fertilization of Xenopus eggs. Nature 342: 505-511.

Watanabe, N., Hunt, T., Ikawa, Y., and Sagata, N. 1991. Independent inactivation of MPF and cytostatic factor (Mos) upon fertilization of Xenopus eggs. Nature 352: 247-248.

Waters, J.C. and Salmon, E.D. 1995. Chromosomes take an active role in spindle assembly. Bioessays 17: 911-914.

Webb, D.J. and Nuccitelli, R. 1981a. Direct measurement of intracellular $\mathrm{pH}$ changes in Xenopus eggs at fertilization and cleavage. J. Cell Biol. 91: 562-567.

- 1981b. Intracellular $\mathrm{pH}$ changes accompanying the activation of development in frog eggs: Comparison of $\mathrm{pH}$ microelectrodes and 31P-NMR measurements. Kroc. Found. Ser. 15: 293-324.

Weiss, E. and Winey, M. 1996. The Saccharomyces cerevisiae spindle pole body duplication gene MPS1 is part of a mitotic checkpoint. J. Cell Biol. 132: 111-123.

Whitfield, W.G.F., Gonzalez, C., Maldonado-Codina, G., and Glover, D.M. 1990. The A- and B-type cyclins of Drosophila are accumulated and destroyed in temporally distinct events that define separable phases of the $\mathrm{G}_{2} / \mathrm{M}$ transition. EMBO I. 9: 2563-2572.

Winey, M. and Huneycutt, B.J. 2002. Centrosomes and checkpoints: The MPS1 family of kinases. Oncogene 21: 61616169.

Winey, M., Goetsch, L., Baum, P., and Byers, B. 1991. MPS1 and MPS2: Novel yeast genes defining distinct steps of spindle 
Tunquist and Maller

pole body duplication. J. Cell Biol. 114: 745-754.

Winkler, M.M., Nelson, E.M., Lashbrook, C., and Hershey, J.W. 1985. Multiple levels of regulation of protein synthesis at fertilization in sea urchin eggs. Dev. Biol. 107: 290-300.

Winston, N., Johnson, M., Pickering, S., and Braude, P. 1991. Parthenogenetic activation and development of fresh and aged human oocytes. Fertil. Steril. 56: 904-912.

Wolf, D.P., Nishihara, T., West, D.M., Wyrick, R.E., and Hedrick, J.L. 1976. Isolation, physicochemical properties, and the macromolecular composition of the vitelline and fertilization envelopes from Xenopus laevis eggs. Biochemistry 15: 3671-3678.

Wyrick, R.E., Nishihara, T., and Hedrick, J.L. 1974. Agglutination of jelly coat and cortical granule components and the block to polyspermy in the amphibian Xenopus laevis. Proc. Natl. Acad. Sci. 71: 2067-2071.

Yamashita, S. and Maller, J.L. 1990. Identification of an activator required for elevation of maturation-promoting factor (MPF) activity by $\gamma$-S-ATP. J. Cell Biol. 110: 1583-1588.

Yen, T.J., Compton, D.A., Wise, D., Zinkowski, R.P., Brinkley, B.R., Earnshaw, W.C., and Cleveland, D.W. 1991. CENP-E: A novel human centromere-associated protein required for progression from metaphase to anaphase. EMBO J. 10: 12451254.

Yew, N., Mellini, M.L., and Vande Woude, G.F. 1992. Meiotic initiation by the mos protein in Xenopus. Nature 355: 649652.

Yim, D.L., Opresko, L.K., Wiley, H.S., and Nuccitelli, R. 1994. Highly polarized EGF receptor tyrosine kinase activity initiates egg activation in Xenopus. Dev. Biol. 162: 41-55.

Zachariae, W., Schwab, M., Nasmyth, K., and Seufert, W. 1998. Control of cyclin ubiquitination by CDK-regulated binding of Hctl to the anaphase promoting complex. Science 282: 1721-1724.

Zecevic, M., Catling, A.D., Eblen, S.T., Renzi, L., Hittle, J.C., Yen, T.J., Gorbsky, G.J., and Weber, M.J. 1998. Active MAP kinase in mitosis: Localization at kinetochores and association with the motor protein CENP-E. J. Cell Biol. 142: 15471558.

Zhu, Y., Bond, J., and Thomas, P. 2003a. Identification, classification and partial characterization of genes in humans and other vertebrates homologous to a novel fish membrane progestin receptor. Proc. Natl. Acad. Sci. (In press).

Zhu, Y., Rice, C.D., Pang, Y., Pace, M., and Thomas, P. $2003 \mathrm{~b}$. Cloning, expression and characterization of a novel membrane progestin receptor and evidence it is an intermediary in meiotic maturation of fish oocytes. Proc. Natl. Acad. Sci. (In press).

Zucker, R.S. and Steinhardt, R.A. 1978. Prevention of the cortical reaction in fertilized sea urchin eggs by injection of calcium-chelating ligands. Biochim. Biophys. Acta 541: 459-466.

Zur, A. and Brandeis, M. 2001. Securin degradation is mediated by fzy and fzr, and is required for complete chromatid separation but not for cytokinesis. EMBO I. 20: 792-801. 


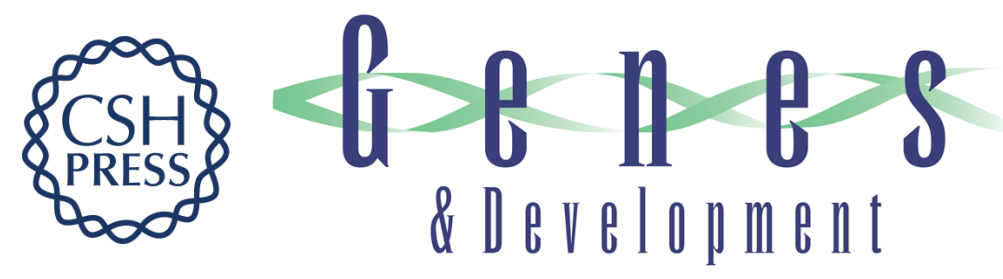

\section{Under arrest: cytostatic factor (CSF)-mediated metaphase arrest in vertebrate eggs}

Brian J. Tunquist and James L. Maller

Genes Dev. 2003, 17:

Access the most recent version at doi:10.1101/gad.1071303

$\begin{array}{ll}\text { References } & \begin{array}{l}\text { This article cites } 299 \text { articles, } 132 \text { of which can be accessed free at: } \\ \text { http://genesdev.cshlp.org/content/17/6/683.full.html\#ref-list-1 }\end{array}\end{array}$

License

Email Alerting Receive free email alerts when new articles cite this article - sign up in the box at the top Service right corner of the article or click here.

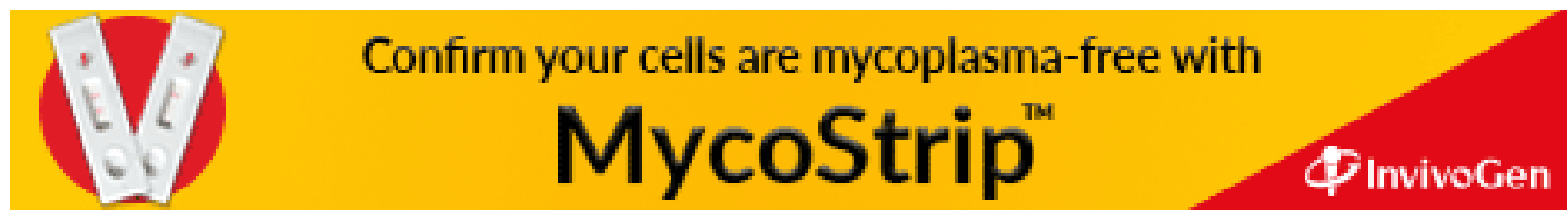

